\title{
Investigating the Effect of Humor Communication Skills Training on Pro-social and Anti-social Humor Styles, Cognitive Learning, Self-efficacy, Motivation, and Humor Use
}

\author{
Lori E. Vela
}

West Virginia University

Follow this and additional works at: https://researchrepository.wvu.edu/etd

\section{Recommended Citation}

Vela, Lori E., "Investigating the Effect of Humor Communication Skills Training on Pro-social and Antisocial Humor Styles, Cognitive Learning, Self-efficacy, Motivation, and Humor Use" (2013). Graduate Theses, Dissertations, and Problem Reports. 5009.

https://researchrepository.wvu.edu/etd/5009

This Dissertation is protected by copyright and/or related rights. It has been brought to you by the The Research Repository @ WVU with permission from the rights-holder(s). You are free to use this Dissertation in any way that is permitted by the copyright and related rights legislation that applies to your use. For other uses you must obtain permission from the rights-holder(s) directly, unless additional rights are indicated by a Creative Commons license in the record and/ or on the work itself. This Dissertation has been accepted for inclusion in WVU Graduate Theses, Dissertations, and Problem Reports collection by an authorized administrator of The Research Repository @ WVU.

For more information, please contact researchrepository@mail.wvu.edu. 
Investigating the Effect of Humor Communication Skills Training on Pro-social and Anti-social Humor Styles, Cognitive Learning, Self-efficacy, Motivation, and Humor Use

\author{
Lori E. Vela \\ Dissertation submitted to the \\ Eberly College of Arts and Sciences \\ At West Virginia University \\ in partial fulfillment of the requirements \\ for the degree of \\ Doctor of Philosophy \\ in \\ Communication Studies \\ Melanie Booth-Butterfield, Ph.D., Chair \\ Rebecca M. Chory, Ph.D. \\ Matthew M. Martin, Ph.D. \\ Christine E. Rittenour, Ph.D. \\ David Westerman, Ph.D. \\ Lauryl A. Lefebvre, Ph.D.
}

Department of Communication Studies

Morgantown, West Virginia

2013

Keywords: Humor orientation, humor styles, cognitive learning, self-efficacy, motivation, humor communication skills training, Social Cognitive Theory

Copyright 2013 Lori E. Vela 


\section{ABSTRACT \\ Investigating the Effect of Humor Communication Skills Training on Pro-social and Anti- social Humor Styles, Cognitive Learning, Self-efficacy, Motivation, and Humor Use}

\section{Lori E. Vela}

Humor is an important aspect of interpersonal interactions as it is linked to the development and maintenance of relationships (Merolla, 2006). The purpose of this dissertation was to test the effect of a humor communication skills training program on the ability to minimize anti-social humor (i.e., aggressive, self-defeating) and enhance pro-social humor (i.e., affiliative, selfenhancing) in interpersonal interactions. Working from the framework of Social Cognitive Theory (Bandura, 1986, 2001), the effect of the humor skills training on self-efficacy, motivation, positive and negative humor use, and cognitive learning were also examined. Data were collected at baseline, post-training, and at a two week follow-up for the comparison group $(n=149)$ and treatment group $(n=152)$. Generally, results indicated that participants in the humor skills training group reported improving in self-enhancing humor, self-efficacy, and cognitive learning, upon completion of the final training session. However, they did not improve in affiliative humor, anti-social humor styles, motivation, or positive humor use. Furthermore, those that completed humor skills training maintained higher levels of self-enhancing humor, self-efficacy, and cognitive learning, two weeks after the final training session. Therefore, humor skills training can influence behavioral change, and this investigation provides a strong starting point for future exploration of the effect of humor skills training in the interpersonal communication context. 


\section{TABLE OF CONTENTS}

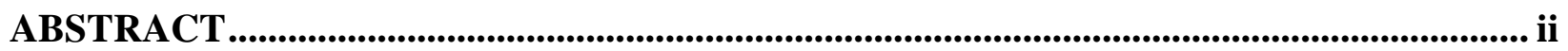

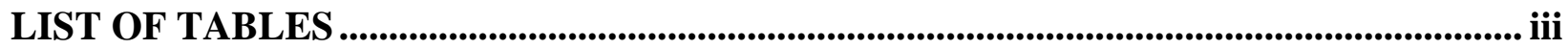

ACKNOWLEDGEMENTS _................................................................................................... vi

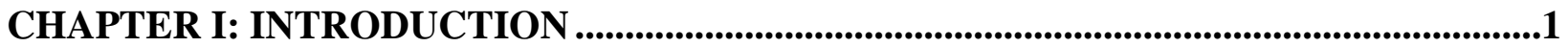

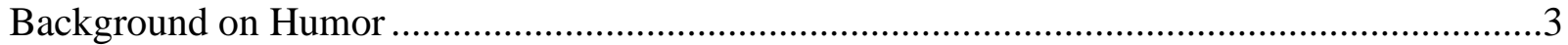

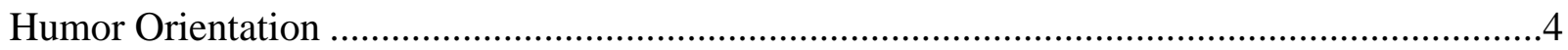

Humor Styles .............................................................................................................

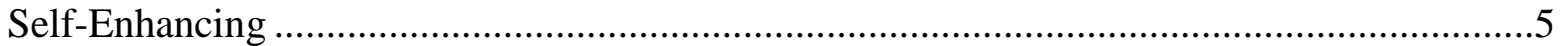

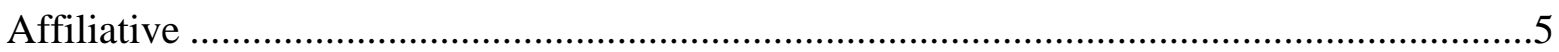

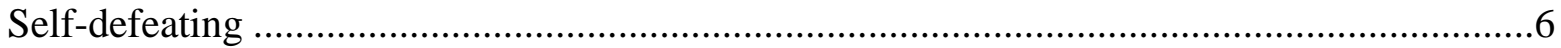

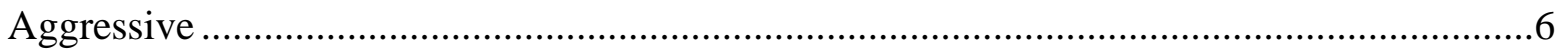

Problem to be Evaluated: Anti-Social Humor.......................................................................

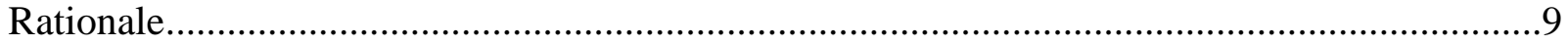

Theoretical Framework: Social Cognitive Theory .............................................................12

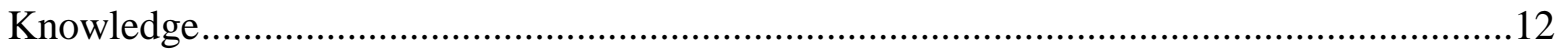

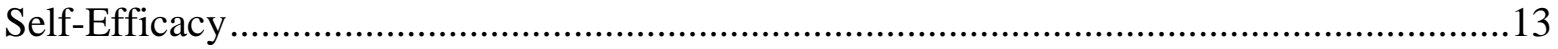

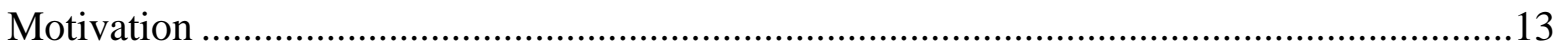

Social Learning Concepts ..............................................................................................14

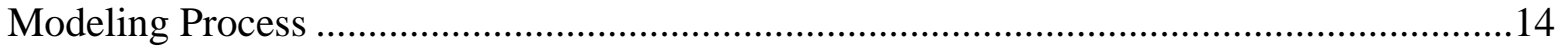

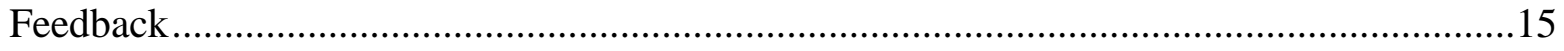

Proposed Solution: Humor Communication Skills Training ………………………............26

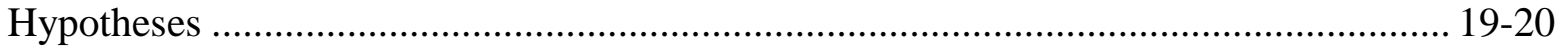

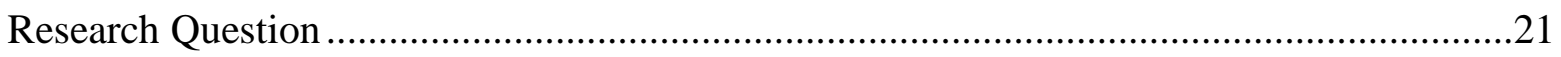

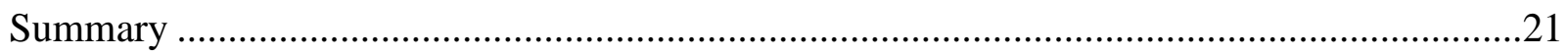

CHAPTER II: METHOD ............................................................................................................22

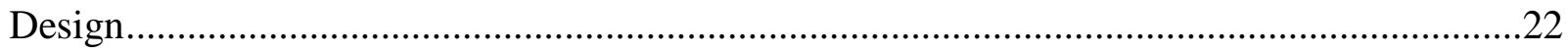

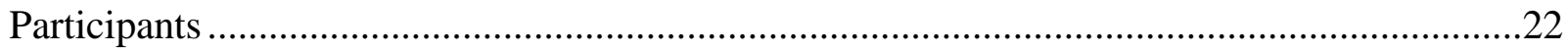

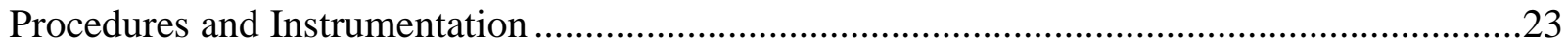

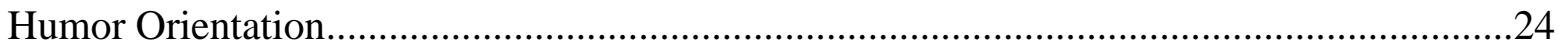




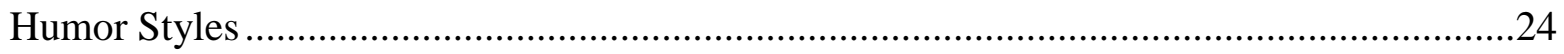

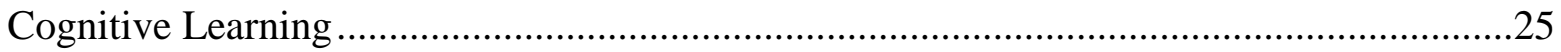

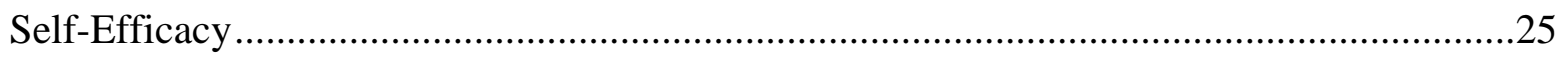

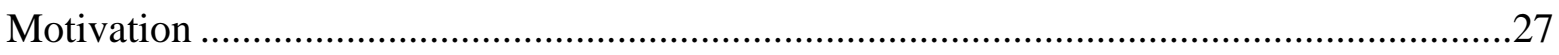

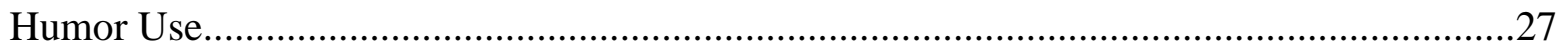

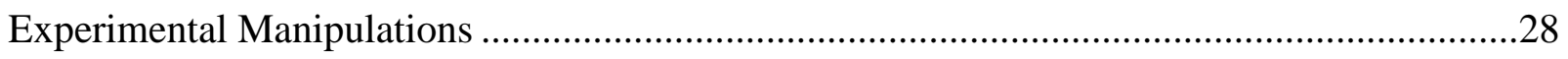

Humor Communication Skills Training ……………………………………………....28

Sexual Communication Skills Training.........................................................................

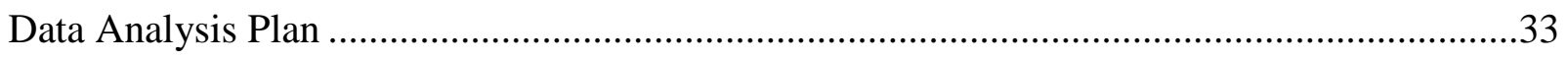

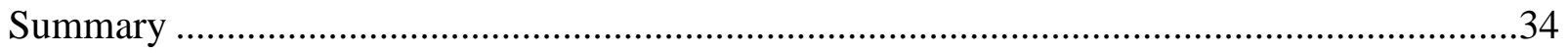

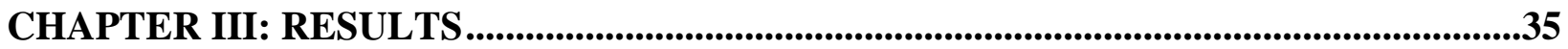

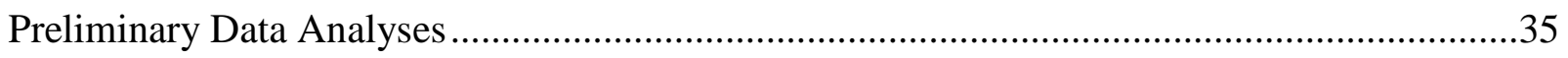

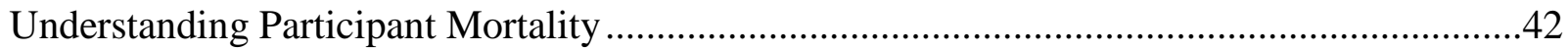

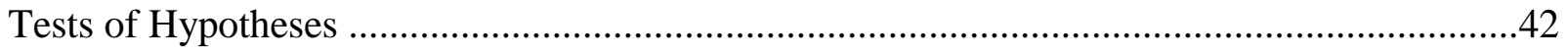

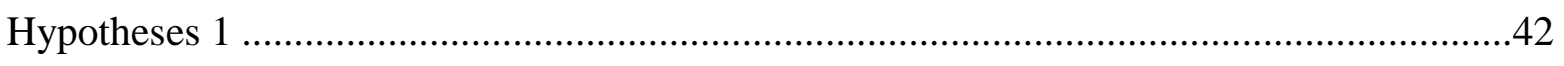

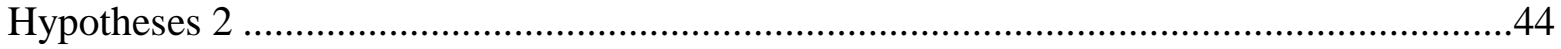

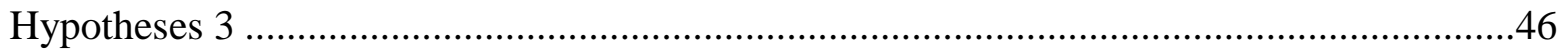

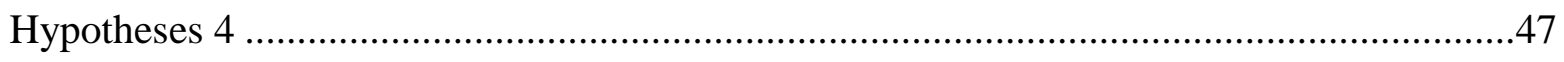

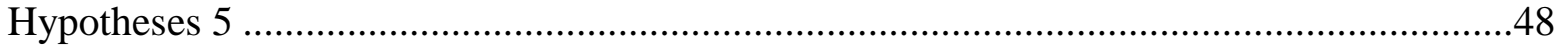

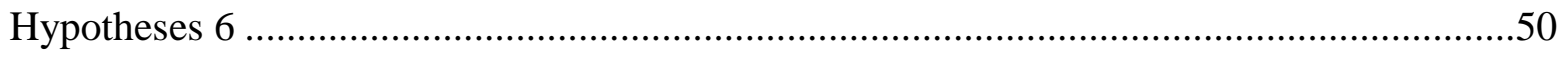

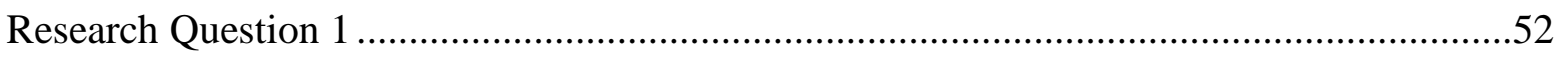

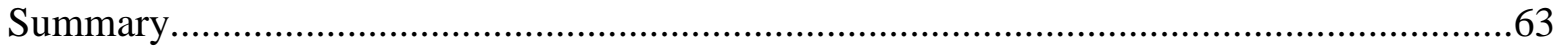

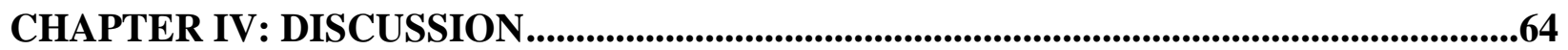

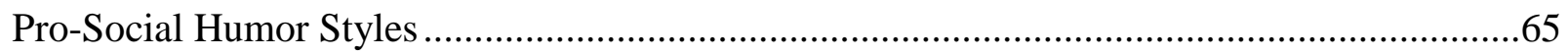

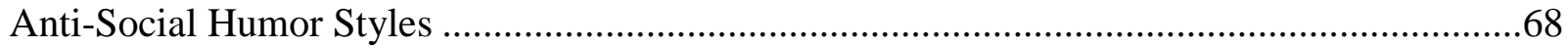

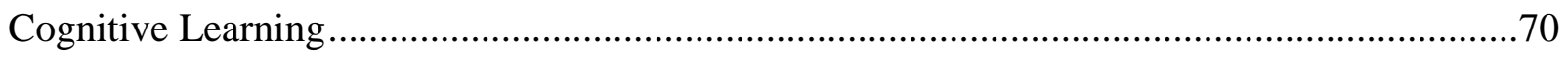

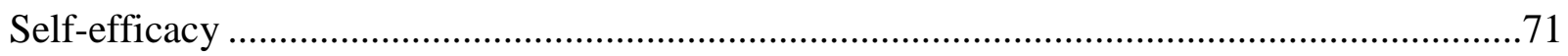

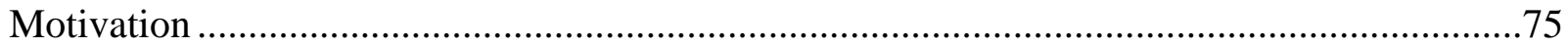

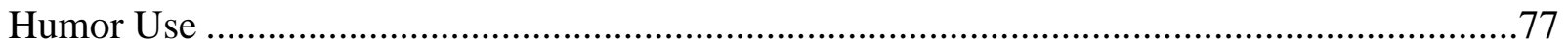

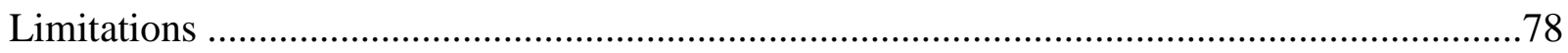

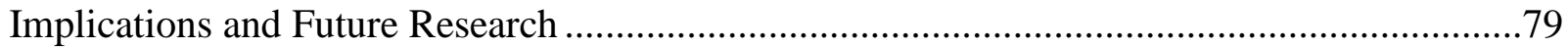




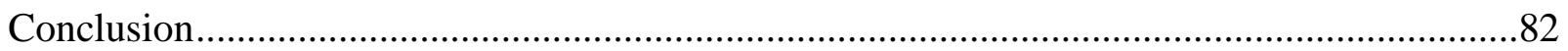

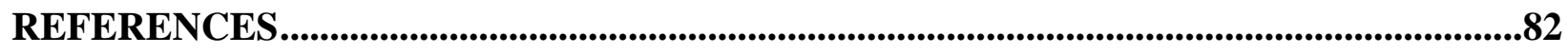

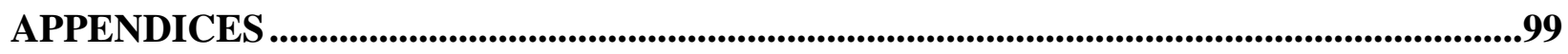

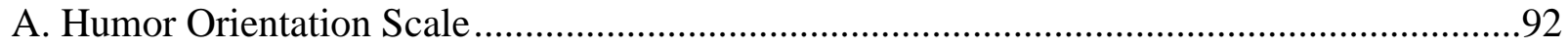

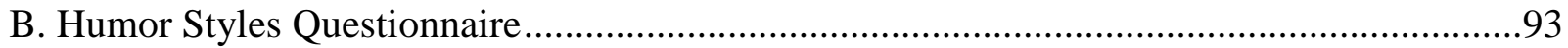

C. Cognitive Learning Assessment ...........................................................................95

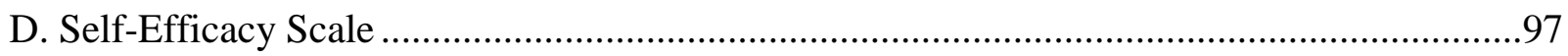

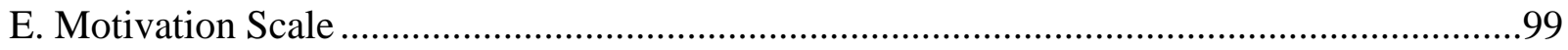

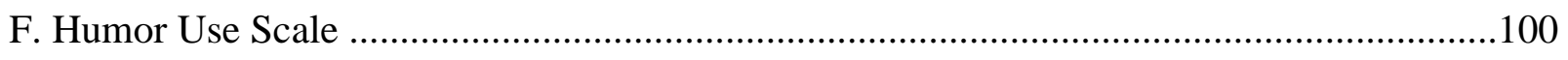

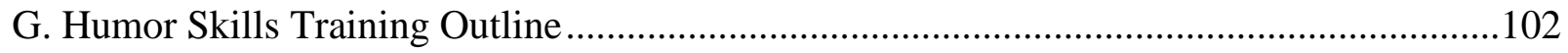

H. Humor Skills Training PowerPoint Presentation ...................................................107

I. Sexual Communication Skills Training Outline .......................................................108

J. Sexual Communication Skills Training PowerPoint Presentation ..................................110

K. Sexual Communication Skills Training Handout .............................................. 111-112 


\section{LIST OF TABLES}

Table 1. Treatment Group, Two-tailed Pearson Correlations at Baseline .....................................43

Table 2. Comparison Group, Two-tailed Pearson Correlations at Baseline ...................................43

Table 3. Treatment Group, Two-tailed Pearson Correlations at Post-Training ..............................44

Table 4. Comparison Group, Two-tailed Pearson Correlations at Post-Training ............................44

Table 5. Treatment Group, Two-tailed Pearson Correlations 2 Week Follow-up...........................45

Table 6. Comparison Group, Two-tailed Pearson Correlations 2 Week Follow-up.......................45

Table 7. Treatment and Comparison Group Baseline Statistics.........................................................46

Table 8. Treatment Group Sex Differences .....................................................................................47

Table 9. Comparison Group Sex Differences ........................................................................48

Table 10. Treatment and Comparison Group Post-Test.................................................................59

Table 11. Treatment and Comparison Group 3 Data Collections .......................................................69 


\section{ACKNOWLEDGEMENTS}

This journey has been the most challenging and rewarding experience of my life. I am forever grateful for a select group of individuals that helped me achieve the greatest goal of earning my Ph.D.

First and foremost, I would like to thank my Advisor, Dr. Melanie Booth-Butterfield. It is only with your endless encouragement, support, and guidance that I was able to be successful. I lost count of the many times I showed up in your office for guidance and even personal support. You always welcomed me with open arms and helped me work through every challenge. I appreciate your constant positive attitude and ability to calm my nerves and boost my spirit. No matter how stressed I ever felt, I always knew that you were on my side cheering me on with your famous saying, "You CAN do this!"

I would also like to thank my committee members, Dr. Martin, Dr. Chory, Dr. Rittenour, Dr. Westerman, and Dr. Lefebvre. Each of you offered endless support and always had an open door policy. I appreciate each and every one of you for your guidance in the program and especially with my dissertation. I am forever grateful for your time and consideration always.

Finally, I would like to thank my family. My mother, Lisa Vela, was my rock and my greatest supporter. Thank you for always encouraging me to follow my dreams. Thank you for always answering the phone at any time of day or night to listen to me and provide support. I love you and I could never thank you enough. Also, I'd like to thank my sisters, Melissa Torti and Alina Rodriguez for always encouraging me and supporting me. I could not have completed my Ph.D. without my sisters by my side. I'd also like to thank my closest friends, Jessalyn Vallade, Shannon Carton, Colleen Malachowski, Kristen Farris, and Daisy Reyes for always being there for me and helping me through this journey. 


\section{Chapter One}

\section{Introduction}

Humor is an important aspect of initiating and maintaining interpersonal relationships (Merolla, 2006). Speaking to the importance of humor in romantic relationships is research indicating that spouses reported positive humor (e.g., humor used to communicate closeness) as one of the most important indicators of a successful marriage (Lauer, Lauer, \& Kerr, 1990). In fact, positive humor has been shown to enhance comfort levels, closeness, as well as perceptions of solidarity and bonding, in marital couples (Bethea, 2001). Although the study of humor in the interpersonal communication context has focused primarily on the role of humor in marriages, recent studies suggest that humor has equally important implications for other types of relationships and interactions (Barelds \& Barelds-Dijkstra, 2010; Bippus, Young, \& Dunbar, 2011).

For instance, in a study investigating the role of humor in dating couples, partners who reported frequent engagement in positive humor with their significant other also reported increased perceptions of intimacy, love, and relationship satisfaction (Barelds \& BareldsDijkstra, 2010). When used among friends, positive humor has been shown to aid in the expression of sensitive information, help diffuse tension, save face, and act as a buffer by protecting against negative emotions evoked by stressful or embarrassing situations (Bippus 2000; 2003). As these findings suggest, the study of humor in the interpersonal context generally focuses on pro-social/positive aspects of humor, with a much smaller body of research focusing on the impact of anti-social/negative aspects of humor (Rancer \& Graham, 2012).

Meyer (2000) argued that humor is a powerful tool that can either unify or divide people. Contrary to the benefits of positive humor, negative humor (e.g., put downs, sarcasm) has been 
linked to demand-withdrawal patterns in husbands and wives, reduced levels of intimacy in married couples, marital dissatisfaction (Alberts, 1990; De Koning \& Weiss, 2002), and relationship dissatisfaction in dating couples (Cann, Zapata, \& Davis, 2009). Negative humor has also been associated with relationship deterioration in friendships and therefore may be harmful for both the sender and receiver of the humorous message in any interpersonal situation (Wanzer, Booth-Butterfield, \& Booth-Butterfield, 1996). How a person communicates and responds to positive and negative humor may have personal and social consequences, and is often directly associated with communication competence (Dereli, 2009).

Communication competence has been defined as, "the ability of an individual to demonstrate knowledge of the situationally appropriate behavior" (Spitzberg, 1983, p. 323). Social environments, peers, relational partners, and instructors play a vital role in the acquisition of communication competence and social skills (Dereli, 2009). As well, the communication behaviors acquired by individuals in college are vital to future behaviors (Dereli). College students often experience expanding social networks, and, consequently, are likely to encounter instances of positive and negative communication, including positive and negative humor.

According to Duran (1992), humor is an important aspect of communication competence and is positively related to perceived social attraction. Likewise, Yip and Martin (2006) argued that the ability to strategically communicate positive humor is an important interpersonal skill in itself, and may contribute to other social competencies such as the ability to initiate friendships and reveal personal information about oneself to others. On the other hand, a lack of communication competence has been linked with negative humor use. For example, individuals who tend to communicate negative humor in general also report a lower ability to provide emotional support to others and to manage conflicts in relationships (Yip \& Martin). Given the 
benefits associated with communication competence and the employment of positive humor, as well as the consequences associated with a lack of communication competence and negative humor, it is important to focus on ways to minimize negative communication (e.g., negative humor) and enhance positive communication (e.g., positive humor) in interpersonal interactions (Halford, 2011).

From a skills development perspective, individuals can become more communicatively competent by engaging in skills training aimed at enhancing specific communication behaviors (Halford, 2011). For instance, relationship education programs focused on teaching dating and married partners to reduce negative communication and enhance positive communication have been successful in improving self-efficacy (Halford). The research investigating training programs is consistent in demonstrating that approximately four hours of communication skills training can have a positive effect on self-efficacy and self-reported behaviors (Halford; Mahin, Noah, Hassan, \& Baba 2012; Rice, 2000). Therefore, similar considerations may be applied to a communication skills training program aimed at enhancing positive humor and minimizing negative humor in the interpersonal communication context.

\section{Background on Humor}

Humor is said to be a fundamental aspect of relating to others (Merolla, 2006). Positive humorous enactments have been conceptualized as "intentional verbal and nonverbal messages which elicit laughter, chuckling, and other forms of spontaneous behavior taken to mean pleasure, delight, and/or surprise in the targeted receiver" (Booth-Butterfield \& BoothButterfield, 1991, p. 206). Because humor plays a vital role in communicative interactions, scholars have investigated humor from a production (i.e., source) and an appreciation (i.e., receiver) approach. A source perspective asserts that a considerable portion of social humor is 
strategic and thus intentional. From this perspective, "communication researchers are able to focus on the communicatively complex ways that sources enact humorous messages" (Wanzer \& Booth-Butterfield, 2012, p. 15). For instance, Booth-Butterfield and Booth-Butterfield coined the term trait humor orientation (HO) to refer to one's predisposition to use humor. Generally, those with a higher HO enact humor more frequently and successfully across various situations, view more situations as appropriate for humor attempts, enact humor without substantial planning, and have a larger personal repertoire of humorous behaviors than lower HOs (BoothButterfield \& Booth-Butterfield; Merolla; Wanzer et al., 1996). Although HO focuses on positive aspects of humor and addresses humor as a pro-social communication-based personality trait, it is important to understand that all humor may not be productive and pro-social.

In an investigation of the functions of humor, or the reasons why people use humor in general, Graham, Papa, and Brooks (1992) found that individuals employed humorous messages to communicate positive affect (e.g., closeness), negative affect (e.g., aggression), and/or to express themselves (e.g., share difficult information). Similarly, in romantic relationships, dating partners reported generally employing humor to communicate positive affect, negative affect, and/or to avoid or minimize a situation or topic (De Koning \& Weiss, 2002). Further examination of the positive and negative functions of humor resulted in the development of the Humor Styles Questionnaire (HSQ) which identifies four dimensions or styles of humor (Martin, Puhlik-Doris, Larsen, Gray, \& Weir, 2003).

\section{Humor Styles}

Compared to HO, humor styles are "less concerned with how people react to different types of situations by using humor and laughter, and more with how individuals use positive and/or negative humor in their daily lives" (Wanzer \& Booth-Butterfield, 2012, p. 16). Martin 
and colleagues (2003) identified two pro-social (i.e., affiliative and self-enhancing) and two antisocial (i.e., aggressive and self-disparaging) types of humor. Each of these will be explained in more detail below.

Pro-social Humor Styles. Pro-social humor styles (i.e., positive humor) are humorous messages used to benefit the self (self-enhancing humor) and to enhance interpersonal relationships (affiliative humor). Specifically, self-enhancing humor is often employed as a coping mechanism to adapt to stressful situations (Martin et al., 2003). For example, someone using self-enhancing humor might tell a joke prior to a stress-invoking interaction (e.g., discussion of a difficult topic) to ease one's own personal stress. Those high in self-enhancing humor generally have a positive outlook on life and are able to use humorous messages when faced with adversity (Kuiper, Martin, \& Olinger, 1993).

Affiliative humor is employed to amuse others, facilitate interpersonal relationships, and reduce tension through the use of light-hearted jokes and witty communication (Martin et al., 2003). For example, someone using affiliative humor might tell a joke to gain liking from a group of people in a social setting, or to relieve the anxiety of a group preparing for a stressful interaction. Those high in affiliative humor generally communicate humorous messages to enhance cohesion and interpersonal attraction (Martin et al.).

Correlational research indicates that both pro-social humor styles are positively related with relational variables, including intimacy, relationship satisfaction, and communication competence. Additionally, because HO involves the use of positive humor, pro-social humor styles have also been positively related with humor orientation (Cann et al., 2009). Higher HOs are perceived as socially attractive, funnier than lower HOs, and have a greater ability to communicatively adapt to various people and situations (Wanzer, Booth-Butterfield, \& Booth- 
Butterfield, 1995; Merolla, 2006). On the other hand, pro-social humor styles are negatively related with loneliness, depression, and anxiety (Frewen, Brinker, Martin, \& Dozois, 2008; Hampes, 2006; Martin, 2007).

Anti-social Humor Styles. Anti-social humor styles (i.e., negative humor styles) are humorous messages used to communicate aggression and to manipulate others (aggressive humor), and humor that is viewed as destructive for the self (self-defeating humor). Specifically, self-defeating humor is employed to gain others' approval through the use of self-disparagement or intentionally being the "butt" of the joke (Martin et al., 2003). For example, someone using self-defeating humor might make negative comments about his/herself to gain approval from another person at the expense of lowered self-esteem. Those high in self-defeating humor tend to be excessive in making themselves the target of a joke, or putting themselves down to gain acceptance by others. Although people who use self-defeating humor may be entertaining, they tend to be emotionally needy and have low self-esteem (Martin et al.).

Aggressive humor is employed to hurt or put others down through the use of sarcasm, teasing, and ridicule (Martin et al., 2003). For example, someone using aggressive humor might tease a relational partner who is having difficulty achieving a task, or may make harsh comments, disguised as humor, toward that person. Those high in aggressive humor generally are not concerned with the impact of their negative comments on others. This can alienate individuals and damage relationships (Janes \& Olson, 2000).

Furthermore, triggers of aggressive humor are prevalent in relationships and interpersonal interactions (Vallade, Booth-Butterfield, \& Vela, 2013). Vallade and colleagues examined humor styles of romantic partners and close friends following relational transgressions (i.e., acts that violate implicit or explicit relationship rules, norms, or expectations) and found that 
individuals reported intentionally producing aggressive humor targeted at the transgressor with the specific purpose of demeaning or belittling him/her, or as a vehicle for making negative comments. Those who reported a higher aggressive humor style also reported more frequent use of negative humor following the hurtful event. Thus, although two people are involved in an interpersonal relationship, they may not always feel favorably about each other, and therefore occasions may arise when aggressive humor is intentionally used (Vallade et al.).

The use of self-defeating humor and aggressive humor styles are often positively correlated. Some researchers regard both negative humor styles as aggressive, suggesting that self-defeating humor uses inward aggression, while aggressive humor uses outward aggression (McCosker \& Moran, 2012). Vallade and colleagues (2013) found that people who reported having a self-defeating humor style also reported using more aggressive humor toward their romantic partner or friend following a hurtful event. This is consistent with previous research indicating that self-reported self-defeating humor is associated with greater levels of hostile communication (Martin et al., 2003).

\section{Problem to be Evaluated: Anti-social Humor}

Humor can have a positive and/or negative effect on the individuals involved in a humorous exchange. Of the four humor styles, aggressive humor poses the greatest threat to interpersonal interactions (Saroglou, Lacour \& Demeure, 2010). Aggressive humor was originally introduced by Zillman (1983) who referred to it as the hostile use of humor to manipulate, tease, or ridicule another person. According to Martin et al. (2003), "although friendly teasing and playful poking fun at others may be a way of enhancing cohesiveness in more benign forms of affiliative humor, the aggressive humor style refers to the uses of humor that are intended to belittle others, albeit often under the guise of playful fun" (p. 52). When 
aggressive humor is communicated, especially in an excessive and/or malicious way, it can be detrimental to relationships (Romero \& Cruthirds, 2006).

Negative Effects of Anti-Social Humor

Anti-social humor is linked to greater use of aggression and hostility in various types of interpersonal exchanges (Martin et al., 2003). For example, in a study conducted by Matthews, Wickrama, and Conger (1996), perceptions of a spouse's aggressive humor were related to increased perceived partner hostility, rejection, and a lack of relational closeness. Saroglou and colleagues (2010) compared self-reported humor styles and relationship satisfaction of married and divorced couples and found that anti-social humor styles predicted divorce and were associated with low retrospective relationship satisfaction in divorced couples. In line with these findings, Cann et al. (2009) found that perceiving a relational partner as using more anti-social humor and less pro-social humor was related to lower levels of relationship satisfaction.

Furthermore, in a study conducted by Campbell, Martin, and Ward (2008), individuals who used anti-social humor styles during a discussion about a difficult topic with a relational partner also reported being less satisfied in the relationship, felt more distant from their partner, experienced more stress during the interaction, and had a lower problem resolution rate than those who employed pro-social humor styles.

Scholars have also examined the psychological and physical outcomes associated with humor styles. Freud (1928) was one of the first to suggest that psychological functioning is associated with distinctive types of humor. According to Freud, positive humor has the potential to contribute to healthy psychological functioning, while negative humor can have the opposite effect and is often harmful to psychological well-being. For example, compared to pro-social humor styles, anti-social humor styles are often related with greater levels of depression (Kuiper 
\& Hale, 2009), psychological distress (Yue \& Goldman, 2010), and stress (Cann \& Etzel, 2008). Those who report using anti-social humor styles also tend to report having less social self-esteem (Kuiper, Grimshaw, Leite, \& Kirsh, 2004; Kuiper \& Hale, 2009), personal self-esteem (Stieger, Formann, \& Burger, 2011), communication competence, and optimism, than those who employ pro-social humor styles. Taken together, these findings indicate that pro-social and anti-social humor styles have the potential to positively or negatively impact intrapersonal and interpersonal communication, as well as relationships.

\section{Rationale}

Humor styles involve the intentional use of humorous messages to express either prosocial or anti-social communication in interpersonal interactions (Martin et al., 2003). The humor style a person enacts sends a strong message about his/her perceived self-efficacy, social competence, and relational goals (Martin et al.). Moreover, the absence of anti-social styles of humor may be just as important as the presence of pro-social humor styles (Martin et al.).

Much like selecting the proper tool from a toolkit, individuals should select the appropriate humor style for various interactions (Romero \& Cruthirds, 2006). For example, affiliative humor may be employed to aid in the initiation of a relationship, while self-enhancing humor may be used to cope with problems. On the other hand, although they are not healthy forms of humor, individuals may strategically enact self-defeating and/or aggressive humor in different situations. Self-defeating humor is often used to hide negative feelings and may be employed to seek acceptance from others at the expense of putting oneself down. Aggressive humor may be used for retaliation purposes, or to intentionally demean or belittle others.

The ways in which people communicate and respond using either pro-social or anti-social humor may be associated with social factors. According to Martin and colleagues (2003), 
positive and negative humor styles are often learned through interactions with others. For instance, individuals learn to enact and respond to messages through communication with family members, peers, instructors, and other interpersonal exchanges. Therefore, it is plausible that people can enhance their humor styles repertoire by learning how to effectively communicate pro-social humor and avoid communicating anti-social humor.

From a theoretical standpoint, it is also reasonable to assume that individuals who typically enact aggressive and/or self-defeating humor can learn to alter these negative behaviors. Social Learning Theory (SLT; Bandura, 1977) was originally based on the assumption that the process of learning occurs through modeling, imitating, observing, and reinforcing behaviors. SLT was later renamed Social Cognitive Theory (SCT; Bandura 1986; 2001), and was reformulated to take into account the role of the learner's cognitions, selfefficacy, and motivation in the social learning process. Generally, SCT suggests that behaviors and communicative responses can be learned and/or changed at any point time.

One way to influence communication behaviors is with skills training (Dereli, 2009). The general goal of communication skills training is to raise awareness of ineffective or antisocial communication behaviors and provide people with alternative pro-social communication strategies (Dereli). For example, based on the premise that individuals employ aggressive communication due to poor social and problem solving skills, communication skills training programs have focused on targeting these deficits and teaching pro-social alternatives to aggressive communication (Feindler \& Engel, 2011). With regard to pro-social and anti-social humor, perhaps a humor communication skills training program could also be an effective means of teaching the skills that would enable people to communicate positive humor styles and avoid communicating negative humor styles. 
Although humor communication skills training is a generally untapped area of research, communication scholars have long advocated for the development of humor communication skills training in a variety of contexts (Booth-Butterfield, Booth-Butterfield \& Wanzer, 2007; Wanzer \& Frymier, 1999). Du Pre (1998) studied humor communication skills training in the health care setting and argued that the choice to use humor is personal and situational, and people do not need to be "born funny" to use and understand humor. Instead, using humor effectively is largely a matter of understanding and following the social rules.

In the instructional context, Booth-Butterfield and colleagues (2007) expressed the importance of a humor communication skills training program designed to help college students employ humor to cope with stress. Additionally, Wanzer and Frymier (1999) called for a training program designed to help instructors learn to enact appropriate humor in the classroom to enhance student learning. Romero and Cruthirds (2006) suggested that humor communication skills training should be conducted for managers and employees in organizations. It was proposed that training materials be designed to teach people how to select appropriate humor styles to achieve specific desired outcomes (i.e., group cohesion).

It is the need for an effective humor communication skills program within the interpersonal context that informs this research. The purpose of this investigation was to test the effect of a humor communication skills training program on participant ability to minimize the use of anti-social humor (i.e., aggressive, self-defeating) and enhance the use of pro-social humor (i.e., affiliative, self-enhancing) in general. The effect of the training on self-efficacy and motivation to communicate positive humor and to avoid communicating negative humor, selfreported positive/negative humor use, and cognitive learning, were also examined. The humor communication skills training program developed for this study was rooted in Social Cognitive 
Theory (SCT, Bandura, 1986; 2001) and empirical evidence, and may lay the foundation for future research seeking to provide scholars and individuals with a practical guide for enhancing interpersonal communication. In order to understand and explore these implications further, it is necessary to discuss the theoretical underpinning of this dissertation in more detail.

\section{Theoretical Framework: Social Cognitive Theory}

Social Cognitive Theory (Bandura 1986; 2001) stems from Bandura’s earlier conceptualization of Social Learning Theory (SLT; Bandura, 1977). Social Learning Theory is rooted in psychology and behaviorism, and originally focused on the ways in which people acquired behaviors through observation of their external environment. Behaviorism purports that behavior is "cued by the stimuli that precede it and shaped and controlled by the reinforcing stimuli that follow it" (Bandura, 1986, p. 12). Thus, SLT would predict that a person's belief that a behavior will result in a particular reinforcement will have a major influence on the likelihood of that person enacting the behavior. Bandura argued that the phrase "learning theory" put too much emphasis on the relationship between observation and behavior, consequences of behavior, and the enactment of imitative modeling. Therefore, Bandura (1986; 2001) reformulated and renamed SLT Social Cognitive Theory (SCT).

\section{Key Aspects of SCT}

SCT takes into account the role of (a) cognitions, (b) self-efficacy, and (c) motivation in the social learning process and acknowledges the individual learner as fully in control of his/her learning experience (Bandura, 1986). Each of these components will be discussed in more detail below.

Knowledge. Cognitive processes play an important role in the acquisition and retention of new behavior patterns. Specifically, "from observing others, one forms a conception of how 
new behavior patterns are performed, and on later occasions the symbolic construction serves as a guide to action" (Bandura, 1977, p. 192). In other words, observation and personal experience are ways that knowledge is cognitively constructed about behaviors. Obtaining knowledge about consequences for particular communication behaviors also teaches people how they should communicate and respond to achieve positive outcomes and avoid negative outcomes. However, the retention of knowledge and skill development is often associated with perceptions of selfefficacy and motivation. Although there are many behaviors that people are certain they can accomplish, they sometimes do not accomplish these things because they lack incentive to do so, or the confidence that they can successfully complete the task (Bandura).

Self-efficacy. Self-efficacy involves perceived confidence in the ability to effectively enact a behavior in order to achieve a desired outcome. According to Bandura, "given appropriate skills and adequate incentives, self-efficacy is a major determinant of people's choice of activities, how much effort they will expend, and of how long they will sustain effort in dealing with a situation" (Bandura, 1977, p. 194). Self-efficacy has a major impact on behavior change because it determines and predicts actual behavior (Bandura). In fact, Bandura argued that self-efficacy is a more powerful predictor of behavior than past performance. It is also linked to motivation.

Motivation. Motivation is primarily concerned with activation and persistence of behavior (Bandura, 1977). Through imagining that behaving in a certain way will produce more anticipated rewards than costs, individuals often generate motivation, or incentive, for engaging in a new behavior or changing a previously learned ineffective behavior (Bandura, 2001). When a prospective behavior is likely to result in a positive reward or favorable outcome, individuals are more likely to be motivated to take action. According to Bandura, perceived rewards 
influence motivation to enact a behavior independent of self-efficacy. Spitzberg (1983) also suggests that it is only through sufficient motivation that enables a person to apply knowledge and skills appropriately and effectively. Therefore, motivation deserves specific attention in communication skills training programs.

\section{Social Learning Concepts}

There are three core concepts at the heart of the social learning process (Bandura, 1977; 1986). First, people learn through observation. Specifically, people learn by observing various types of models including: (a) live models, (b) instructional models, and/or (c) symbolic models. The live model demonstrates a specific behavior that is observed by the learner. The instructional model describes and/or explains a particular behavior. The symbolic model teaches a behavior via a mediated source (e.g., television). In the current study, an instructional model (i.e., the researcher) conducted a humor communication skills training program. Symbolic models (e.g., video examples) were also used throughout the training program.

Second, mental states impact learning. This suggests that intrinsic motivation (e.g., an internal sense of accomplishment) influences learning and behavioral change. Third, learning does not necessarily lead to behavioral change. According to Bandura $(1977 ; 1986)$, not all behaviors that are observed are internalized and imitated. The learning process and motivation play a role in the decision to internalize and enact behaviors.

\section{The Modeling Process}

In order to enhance the chances of learning, a four phase modeling process involving the observation model and the learner should be considered. First, the learner must pay attention to the model. If the learner is interested in the behavior being discussed there is a greater chance that the learner will be engaged and internalize the information. Second, the learner must be able 
to retain the information. The information must be presented in a way that the learner can build new schemas, internalize, and remember. Thus, retention involves the ability to mentally store information and draw from this repertoire of behaviors at any point in time (Bandura, 1986).

Third, the learner must be able to perform the behavior. Practicing the learned behavior is the most effective means of skill building. For example, Burke and Day (1986) applied SCT and found that incorporating role play into training was an effective form of modeling and practice for trainees. Practicing the behavior also increased participant perceptions of selfefficacy. These findings are consistent with Bandura's (1977) suggestion that actual performance of an activity is the most influential source of self-efficacy.

Fourth, the learner must be motivated to perform the behavior. Understanding the consequences and/or rewards associated with a behavior are important sources of motivation. If a behavior is expected to result in a positive outcome, rather than a negative outcome, individuals will be more likely to be motivated to engage in the behavior (Bandura, 1977; 1986). In the current study, the humor communication skills training program focused on the key aspects of SCT (i.e., knowledge, self-efficacy, and motivation), and applied the four-step modeling process as a means of training individuals to maximize the use of pro-social humor and minimize the use of anti-social humor in interpersonal interactions.

\section{Feedback and SCT}

SCT predicts that successfully engaging in the social learning process has implications for enhancing memory through observation of modeling, practicing behaviors, and increasing self-efficacy and motivation. Additionally, Wexley and Latham (1991) proposed a similar social learning model that focuses on feedback, motivation, and self-efficacy. According to Wexley and Latham, skills may be enhanced by (a) introducing trainees to the topic, (b) providing a 
model to observe, (c) allowing the chance to practice new skills, and (d) providing feedback regarding the skills learned. Adding the component of trainer feedback has been shown to be a successful means of motivating trainees. For instance, when participants were provided with positive feedback for practicing or modeling effective behaviors, the positive reinforcement increased perceptions of motivation and self-efficacy (Wexley \& Latham). Consistent with this research, Bandura (1977) stated, "in the enhancement of previously learned behavior, reinforcement is conceived of mainly as a motivational device" (p. 193). Acknowledging the successful use of a new skill through the feedback process demonstrates that the skill is becoming perfected, which may enhance self-efficacy and motivation (Bandura).

\section{Proposed Solution: Humor Communication Skills Training}

One potential solution for teaching individuals to use more pro-social styles of humor and avoid the use of anti-social styles of humor, that has yet to be examined in the communication discipline, is humor communication skills training. Because research indicates that general communication skills training, conflict resolution training, and anger management training can be used to teach individuals to use more pro-social forms of communication, it should follow that humor communication skills training also has the potential to aid people in developing positive humor skills, or transforming the general use of negative humor into more pro-social communication.

Currently, research exploring the effects of humor skills training has been conducted primarily in the health context and has focused on enhancing sense of humor in an effort to manage negative health-related symptoms (e.g., McGhee 1996; 1999). For example, McGhee (1996) developed a training program aimed at teaching people how to develop eight basic skills required to employ humor to cope with stressful and challenging medical situations. 
Specifically, the program focuses on providing individuals with the skills to effectively (1) determine a person's unique sense of humor, (2) become less serious and develop a more playful attitude, (3) develop a more hearty and healthy laugh, (4) improve joke-telling skills, (5) create and employ spontaneous verbal humor, (6) find humor in everyday life, (7) laugh at yourself, and (8) apply humor skills to cope with stressful and/or challenging situations (McGhee). Although the main goal of the training program is to enhance one's sense of humor, many of the topics are aimed at developing humor enactment skills (e.g., create spontaneous verbal humor). Thus, perhaps similar components could also be applied to humor skills training in the interpersonal communication context.

Crawford and Caltabiano (2011) investigated whether the topics from McGhee’s (1996) training program were effective for training individuals to use humor to cope with negative health-related symptoms. Participants, individuals dealing with a serious illness, who underwent the training experienced greater emotional well-being, self-efficacy, positive thinking, optimism, control, fewer negative thoughts, and less stress, depression, and anxiety, than those who did not go through the program. Similarly, Falkenberg, Buchkremer, Bartels, and Wild (2010) applied the topics from McGhee's training program to depressed adults and found that after completing the humor skills training, participants reported a significant improvement in their state and trait cheerfulness, as well as coping efficacy.

In the interpersonal context, the majority of the skills training research focuses primarily on conflict resolution skills. For example, Halford et al. (2010) found that newlywed couples who completed a communication skills training program focusing on building relationship and conflict communication skills, reported reduced levels of overall negative communication between spouses, reduced conflict communication, and increased marital satisfaction. The four- 
hour training involved informational sessions taught by the trainer and couple discussions of the material. Similarly, Mahin and colleagues (2012) examined the effects of communication and conflict resolution skills training on marital satisfaction. The training sessions included knowledge segments in which participants were provided with information on how to manage conflict with a spouse, and a skills component in which participants engaged in role playing to practice the skills learned. Marital partners reported improved marital satisfaction after completing the six hour training program (Mahin et al.).

Another form of effective skills training is anger management training. Aggression involves social, emotional, and cognitive aspects (Feindler \& Engel, 2011). One major target of anger management training is adolescents. Aggressive youth possess underdeveloped problemsolving and social skills, which can cause anti-social communication, social alienation, anxiety, and withdrawal (Glick, 2003). Selda and Ferda (2011) examined the effect of anger management training on communication skills and anger control of adolescents (15-16 year olds). Participants completed one 90 minute training session each week for 12 weeks. A pre-test/post-test research design was used and revealed a decrease in trait anger, and an increase in anger control level (i.e., anger coping) upon completion of the program.

Generally, communication skills training appears to be an effective means of enhancing various aspects of communication in the health, instructional, and interpersonal contexts. Feindler and Engel (2011) investigated the number of anger management skills training sessions necessary to cause a change in participant attitudes and found a significant increase in positive behavior after a single 90 minute training session. A greater increase was revealed after participants engaged in the second 90 minute training session. Additionally, relationship education programs focused on teaching people to reduce negative communication and enhance 
positive communication in general, have been successful in improving self-efficacy (Halford, 2011).

Collectively, research indicates that an average of four hours of communication skills training can improve self-efficacy and related behavioral outcomes (Halford, 2011). In the current study, similar findings were predicted for a humor communication skills training program. That is, humor communication skills training is expected to be effective in diminishing the use of anti-social humor (i.e., aggressive, self-defeating) and enhancing the use of pro-social humor (i.e., affiliative, self-enhancing).

Furthermore, humor orientation is a trait that may be particularly influential when examining the effects of the humor communication skills training program. $\mathrm{HO}$ is a predisposition to effectively enact humor across a variety of contexts and focuses mostly on the enactment of pro-social humor (Booth-Butterfield \& Booth-Butterfield, 1991). Collective research indicates positive correlations between $\mathrm{HO}$ and pro-social humor styles, and negative correlations between $\mathrm{HO}$ and anti-social humor styles. Therefore, individuals who have a higher humor orientation may be more impacted by humor communication skills training because they are already more likely to enact positive humor across situations (Cann et al., 2009). In contrast, individuals with a lower HO may be more resistant to training because they do not typically enact positive humor in various situations. Thus, $\mathrm{HO}$ was included as a covariate in each of the hypotheses and the research question that are as follows:

\section{Hypotheses}

H1: Humor communication skills training will affect humor styles such that individuals in the treatment group will report (a) more pro-social humor (i.e., affiliative and self- 
enhancing) than those in the comparison group, and (b) an increase in pro-social humor scores from the pre-test to the post-test.

H2: Humor communication skills training will affect humor styles such that individuals in the treatment group will report (a) less anti-social humor (i.e., aggressive and selfdefeating humor) than those in the comparison group, and (b) a decrease in anti-social humor scores from the pre-test to the post-test.

H3: Humor communication skills training will affect cognitive learning such that individuals in the treatment group will report (a) more cognitive learning than those in the comparison group, and (b) an increase in cognitive learning scores from the pre-test to the post-test.

H4: Humor communication skills training will affect self-efficacy such that individuals in the treatment group will report (a) more self-efficacy to enact positive humor and avoid the enactment of negative humor than those in the comparison group, and (b) an increase in self-efficacy scores from the pre-test to the post-test.

H5: Humor communication skills training will affect motivation such that individuals in the treatment group will be report (a) being more motivated to enact positive humor and avoid the enactment of negative humor than those in the comparison group, and (b) an increase in motivation scores from the pre-test to the post-test.

H6: Humor communication skills training will affect humor use such that individuals in the treatment group will report (a) using more positive humor and avoiding negative humor more than those in the comparison group, and (b) an increase in humor use scores from the pre-test to the post-test. 
Despite the quantity of communication skills training research, "few studies have examined maintenance of behavior change at follow-up" (Feindler \& Engel, 2011, p. 249). Although humor communication skills training may impact scores on a post-test measure immediately following the last training session, it is also important to examine the effects of the training after the program has ended (Crawford \& Caltabiano, 2011). Therefore, the following research question was posed:

RQ1: How will humor communication skills training affect humor styles, cognitive learning, self-efficacy, motivation, and humor use two weeks after the training program?

\section{Summary}

This study applied Bandura's $(1986 ; 2001)$ Social Cognitive Theory to a new communication context - humor communication skills training. Specifically, the investigation examined the effects of a humor communication skills training program on pro-social (i.e., affiliative and self-enhancing humor) and anti-social (i.e., aggressive and self-defeating humor) humor styles. The impact of the humor skills training on cognitive learning, self-efficacy, motivation, and self-reports of positive and negative humor use, were also explored. This study may serve as a foundation for future research aimed at helping individuals communicate more positive rather than negative humorous messages to enhance interpersonal relationships. Further, the humor communication skills training program developed for the current study may be applied across a variety of contexts including the interpersonal, instructional, and organizational settings. Thus, this study offers valuable insight to communication scholars interested in the effects of humor communication skills training. The following chapter will explain, in depth, the methods utilized in this study. 


\section{Chapter Two}

\section{Method}

The purpose of this study was to investigate the effect of humor communication skills training on humor styles, cognitive learning, self-efficacy, motivation to enact positive humor and avoid enacting negative humor, and self-reported positive/negative humor use. The following sections describe the overall study design followed by participant information, procedures and instrumentation, and data analysis methods.

\section{Design}

A quasi-experimental pre-test/post-test design was used. This design is widely used in behavioral research for comparing groups and measuring changes over time (Dimitrov \& Rumrill, 2003). Additionally, this design provides greater confidence in the results and indicates the treatment as the primary change agent (Dimitrov \& Rumrill). In the current investigation, humor communication skills training was the independent variable and sexual communication skills training was the comparison. The dependent variables were pro-social humor styles (i.e., affiliative and self-enhancing), anti-social humor styles (aggressive and self-defeating), cognitive learning, self-efficacy, motivation, and self-reported humor use. Additionally, HO was a covariate.

\section{Participants}

Following IRB approval, undergraduate students who were at least 18 years of age and enrolled in one of three sections of the same introductory communication course were solicited for participation during the spring 2013 semester. Previous research indicates that approximately four hours of communication skills training can achieve statistically significant effects on behavioral and communicative outcomes (e.g., self-efficacy; Askari, Noah, Hassan, \& Baba, 
2012; Rice, 2000). Therefore, participants in this study were asked to attend three training sessions, each 75 minutes in length, totaling 3.75 hours.

Students in sections $001(n=95)$ and $002(n=57)$ of an interpersonal communication course were assigned to the treatment group (i.e., humor communication skills training; $n=152$ ). Participants in section 003 of the course were assigned to the comparison group (i.e., sexual communication skills training; $n=149)$. Of those recruited, 301 participants (153 men, 148 women) completed just the Time 1 and Time 2 data collections. They ranged in age from 18 to 31 years $(M=20.05, S D=1.93)$, and consisted of 102 freshmen, 71 sophomores, 72 juniors, and 52 seniors. Four reported their class rank as "other." The majority were Caucasian (82.7\%; Asian 2.3\%; Native American 2.0\%; Black/African American 5.6\%; Hispanic/Latino 2.3\%; and other $5.0 \%$ ).

The final sample consisted of 210 participants (105 men, 105 women) who completed all three data collections. They ranged in age from 18 to 31 years $(M=20.05, S D=1.93)$, and consisted of 76 freshmen, 47 sophomores, 48 juniors, and 39 seniors. The majority were also Caucasian (82.9\%; Asian 2.4\%; Native American 1.9\%; Black/African American 5.7\%; Hispanic/Latino 2.4\%; and other 4.7\%).

\section{Procedures and Instrumentation}

Data collection occurred at three points in time for individuals in the treatment and comparison group. At the initial data collection, Time 1, a pre-test was administered prior to communication skills training. The second data collection, Time 2, took place immediately following the final training session. Approximately two weeks later, the final data collection, Time 3, was conducted. Although all responses were confidential, participation in each data collection was tracked using a participant-generated unique identification code. This was a six 
digit number that consisted of the last four digits of their phone number followed by their two digit birth month. Participants were asked to provide this number at the top of all three questionnaires to allow data to be matched.

Time 1. The initial data collection took place during regularly scheduled class periods in groups ranging from 57 to 152 participants. After reviewing and signing an informed consent form, the pre-test was completed. It included measures assessing humor orientation, humor styles, self-efficacy, motivation, humor use, and cognitive learning. These measures are described in more detail below.

Humor orientation. Humor orientation was assessed using Booth-Butterfield and Booth-Butterfield's (1991) 17-item Humor Orientation Scale (Appendix A). This instrument is used to evaluate one's predisposition toward the use of humor regularly across social interactions (e.g., "I regularly tell jokes and funny stories when in a group"). Responses were recorded on a 5-point Likert scale ranging from strongly disagree (1) to strongly agree (5). Cronbach's alpha in the present investigation was $.90(M=3.84, S D=.53)$ and item scores ranged from 1.94 to 5.00 .

Humor styles. Humor styles were measured using Martin et al.’s (2003) 32-item Humor Styles Questionnaire (Appendix B). This instrument is used to evaluate four styles of humor including two pro-social styles (i.e., self-enhancing and affiliative humor), and two anti-social styles (i.e., self-defeating and aggressive humor). Eight items are used to assess each of the four dimensions: self-enhancing humor (e.g., "If I am upset or unhappy I usually try to think of something funny about the situation to make myself feel better"), affiliative humor (e.g., "I enjoy making people laugh"), self-defeating humor (e.g., "I let people laugh at me or make fun at my expense more than I should"), and aggressive humor (e.g., "If I don't like someone, I often use 
humor or teasing to put them down"). Responses were recorded on a 5-item Likert scale ranging from strongly disagree (1) to strongly agree (5). Item scores ranged from 2.38 to 5.00 for affiliative humor $(\alpha=.78, M=4.22, S D=.50) ; 1.25$ to 4.88 for self-enhancing humor $(\alpha=.81$, $M=3.50, S D=.65), 1.38$ to 4.63 for aggressive humor $(\alpha=.71, M=2.89, S D=.62)$, and 1.00 to 3.50 for self-defeating humor $(\alpha=.79, M=2.64, S D=.67)$.

Cognitive learning. A cognitive learning assessment was developed for this study to address the knowledge/cognition component of Social Cognitive Theory (Bandura, 1986; 2001). Twelve multiple-choice items, each with four response items, were designed to assess knowledge of the cognitive learning objectives associated with the humor communication skills training (Appendix C). A sample item includes, "Which of the following is/are less concerned with how people react to different types of situations by using humor and laughter, and more on how individuals use positive and/or negative humor in their daily lives: a) humor orientation b) humor style c) humor personality d) humorous individuals. In this example, the correct response was humor style. Scores for each item were dichotomous (i.e., correct or incorrect) and KR-20 reliability analysis for the pre-test revealed a .65, which is considered satisfactory for short 10-15 item tests (Kehoe, 1995).

Self-efficacy. In line with Bandura's (2006) guide for constructing self-efficacy scales, a 16-item measure was constructed to assess beliefs regarding individuals' capabilities to communicate positive humor and avoid the enactment of negative humor. According to Bandura, people may judge themselves as efficacious across a wide range of situations or only in specific situations. Therefore, items on the efficacy scale should be adapted to the specific context in which efficacious behaviors are being evaluated. In the current investigation, at the top of the self-efficacy scale were definitions of positive and negative humor. Positive humor 
was defined as "humor that involves intentional verbal and nonverbal messages that elicit pleasure, delight, and/or surprise in the receiver (e.g., lighthearted joke; Booth-Butterfield \& Booth-Butterfield, 1991)." Negative humor was defined as "humor that involves intentional verbal and nonverbal messages used to communicate aggressive messages and/or manipulate others (e.g., putdown, sarcasm; Martin et al., 2003).”

Participants were asked to respond to 16 items created especially for this study (Appendix D). Eight items assessed self-efficacy to enact positive humor (e.g., "How confident are you in your ability to use positive humor in daily conversation"), and eight items assessed self-efficacy to avoid the enactment of negative humor (e.g., "How confident are you in your ability to avoid using negative humor in a stressful situation") in interpersonal interactions. Individuals were asked to rate their confidence in performing each behavior on a scale ranging from cannot do at all (0) to highly certain can do (10).

Because this self-efficacy scale was developed for this study, an exploratory factor analysis (EFA) was performed. One commonly used communication criteria for EFA is that of Comrey and Lee (1992), which suggests that eigenvalues must exceed 1.0 for retained factors, with primary factor loadings of 0.50 or greater and no secondary loadings greater than 0.30 . Based on these criteria, a two-factor solution was obtained for this measure. As expected, all items that loaded on the first factor assessed self-efficacy to avoid enacting negative humor, while all items on the second factor assessed self-efficacy to enact positive humor in interpersonal interactions. Item scores on the subscale assessing self-efficacy to enact positive humor ranged from 5.31 to $8.59(\alpha=.89, M=7.14, S D=1.10)$. The subscale measuring efficacy to avoid enacting negative humor had a Cronbach's alpha of .91. Item scores ranged from 5.65 to $7.58(M=6.68, S D=.33)$. 
Motivation. Motivation was assessed with an adapted version of Duran and Spitzberg's (1995) Motivation Scale (Appendix E). Participants responded to an 8-item measure assessing the desire to enact positive humor and avoid enacting negative humor in interpersonal interactions. Sample items included, "I am self-motivated to use positive humor" and "I want to avoid using negative humor in most situations." Responses were recorded on a 5-point Likert scale ranging from strongly disagree (1) to strongly agree (5).

Again, because this scale was modified for this study, an exploratory factor analysis was conducted. As expected, all of the items that loaded on the first factor assessed motivation to avoid using negative humor, while all items on the second factor assessed motivation to use positive humor in interpersonal interactions. However, applying the criteria for EFA suggested by Comrey and Lee (1992), one item was deleted from the first factor with a primary factor loading below 0.50 , and one item was deleted from the second factor with a secondary loading greater than 0.30 . Item scores on the subscale assessing motivation to enact positive humor ranged from 1.00 to $5.00(\alpha=.81, M=3.85, S D=.67)$. The subscale measuring motivation to avoid the enactment of negative humor had a Cronbach's alpha of .84. Item scores ranged from 1.00 to $5.00(M=3.68, S D=.93)$.

Humor use. Humor use was measured with a 6-item scale developed for this study (Appendix F). The measure assessed self-reports of positive humor use and avoidance of negative humor use. Sample items include, "In the last four weeks I used positive humor effectively in a variety of situations" and "In the last four weeks I avoided using negative humor in a variety of situations." Responses were recorded on a 5-point Likert scale ranging from strongly disagree (1) to strongly agree (5). 
Because this scale was developed for this study, an exploratory factory analysis was conducted. Once more, the criteria for EFA suggested by Comrey and Lee (1992) were applied. As expected, all of the items that loaded on the first factor assessed positive humor enactment, while all items on the second factor assessed avoidance of negative humor enactment. Item scores on the subscale assessing positive humor use ranged from 2.33 to 5.00 ( $\alpha=.83, M=4.24$, $S D=.66)$. The subscale measuring the avoidance of negative humor had a Cronbach's alpha of .91. Item scores ranged from 1.00 to $5.00(M=3.46, S D=.88)$.

Experimental manipulations. Subsequent to obtaining baseline data, participants in the treatment group received humor communication skills training consisting of three 75 minute training sessions over a two week period. The comparison group did not receive humor communication skills training, however, they received sexual communication skills training entailing three 75 minute sexual communication training sessions. The consistency of the overall organization and structure of the humor skills training and the sexual communication skills training sessions were similar. The following explains each of the training programs in more detail.

Humor communication skills training. The humor communication skills training program began with an introduction of the researcher and the topic to be discussed. Participants were informed that over the next three 75 minute training sessions they would learn how to enhance their interpersonal communication skills, specifically with regard to humorous communication. The researcher then encouraged everyone to attend all training sessions. Next, because parts of the training required people to work in small groups, an ice-breaker activity was conducted to allow participants to get better acquainted with each other as well as the researcher. Participants were instructed to introduce themselves to at least three other people. Following the 
ice-breaker activity, the researcher provided participants with an outline and asked them to use it to take notes throughout the training program (Appendix G). This outline was designed in conjunction with a PowerPoint presentation utilized by the researcher during an interactive lecture (Appendix H). The lecture began by identifying the objectives of the training program.

Objectives. The objectives for the humor communication skills training program were based on the three key aspects of Bandura's (1986; 2001) Social Cognitive Theory (i.e., cognition/knowledge, self-efficacy, and motivation). The objectives for the study were as follows: after completing the humor communication skills program, participants will be able to: (a) delineate between pro-social and anti-social humor (cognitive/knowledge), (b) feel confident in their ability to effectively communicate positive humorous messages and avoid communicating negative humorous messages (self-efficacy), and (c) demonstrate a desire to enact pro-social humor and avoid enacting anti-social humor in general (motivation).

Cognition/Knowledge. The PowerPoint presentation specifically focused on the cognition/knowledge component of SCT. First, distinctions were made between humor orientation and humor style. For example, students were informed that whereas humor orientation is a trait based construct that refers to one's predisposition to use humor effectively in various situations (Booth-Butterfield \& Booth-Butterfield, 1991), humor style is a state based construct that focuses on how people enact positive and negative humor in general. Second, definitions and examples were presented for each of the humor styles (i.e., affiliative, selfenhancing, aggressive, and self-defeating). Third, participants were informed about self-efficacy and motivation to communicate positive humor and avoid negative humor. The effects of prosocial and anti-social humor on interpersonal interactions and relational outcomes were also discussed. 
Self-efficacy. Video examples were utilized to portray pro-social and anti-social humor in interpersonal relationships. For example, to depict aggressive humor, the researcher showed a video clip of a woman using sarcasm and putdowns to get back at her best friend who had committed an act of betrayal. The clip ended with the two friends arguing and the relationship deteriorating. Following the video clip, participants were asked to work in small groups of 4-5 and identify the humor style shown in the clip as well as alternative positive humorous approaches to the situation. Each group was then instructed to share their opinions with the entire class. The researcher provided feedback to each group.

An activity was also conducted to allow participants to practice employing pro-social humor and avoiding anti-social humor in stressful situations. The researcher divided the class into small groups of 4-5 and provided each group with a poster board and markers. The groups were then instructed to engage in a brainstorming session for approximately 5 minutes and identify as many aggressive humor triggers as possible (e.g., infidelity, hurtful messages). A spokesperson from each group presented the poster to the class and discussed the triggers. This activity raised awareness of various situations and circumstances that could potentially trigger aggressive humor and encouraged individuals to build upon their confidence, or self-efficacy, when dealing with difficult situations. Moreover, developing knowledge and self-efficacy are both predictors of motivation (Bandura, 1986).

Motivation. A role-playing exercise was conducted in small groups of 3-5 to motivate participants to enhance their communication of pro-social humor and minimize the enactment of anti-social humor. First, participants were asked to think about a time in the last four weeks when they had communicated or witnessed someone else communicating positive or negative humor. Next, students were instructed to discuss the situation with their group members and 
create a reenactment of each scenario. Finally, for those enacting anti-social humor, participants discussed and then reenacted alternative pro-social ways to approach the situation in the future. The goal of this activity was to allow participants to practice using positive humor which could potentially motivate them to continue using these positive behaviors in future interpersonal interactions.

Sexual communication skills training. Sexual communication skills training was selected as the comparison group based on the ability to associate the training with Bandura's (1986; 2001) Social Cognitive Theory. Similar to the humor communication skills training group, those in the sexual communication skills training group were also presented with information pertaining to the three key aspects of SCT: knowledge, self-efficacy, and motivation. Furthermore, sexual communication skills training is important because research shows that open communication between relational and sexual partners is positively related to relationship satisfaction, and safe sexual behaviors (e.g., condom use; Harper \& Welsh, 2007). Sexual communication is also associated with lower rates of sexually transmitted infections and unplanned pregnancies. The information presented in the sexual communication skills training is also relevant to the characteristics of the study sample, college students (Harper \& Welsh).

The training program began with an introduction of the researcher and the topic to be discussed. Participants were informed that over the next three 75 minute training sessions they would learn how to enhance their interpersonal communication skills, specifically with regard to discussing sexual communication issues. Participants were encouraged to attend all training sessions. Because parts of the training required people to work in small groups, an ice-breaker activity was conducted to allow students to get better acquainted with each other as well as the researcher. Specifically, participants were instructed to introduce themselves to at least three 
other people. Next, the researcher provided participants with an outline adapted from BoothButterfield (2012; Appendix I). The outline was designed to be completed in conjunction with information displayed in a PowerPoint presentation during an interactive lecture (Appendix J). Participants were also provided with a handout (Appendix K) designed to help them practice sexual communication as described in more detail below.

Cognitive/Knowledge. The sexual communication skills training focused on two areas of consenting sexual communication: how people initiate and negotiate early sexual interaction (e.g., discussion of sexually transmitted infections, risky sex), and how people in monogamous sexual relationships can communicate more effectively about sex. Utilizing a PowerPoint presentation, the researcher first presented definitions of intimacy and sexuality. Second, the researcher discussed statistics of sexually active young adults. Information was also presented on alcohol and risky sex, male/female differences in behaviors and attitudes toward sex, and negotiating sexual intimacy. Third, participants were given tips on how to communicate more effectively with a sexual partner and engaged in experiential learning activities in an effort to build confidence, or self-efficacy, discussing sex-related issues.

Self-efficacy. To ensure that participants felt efficacious in their ability to effectively communicate about sexual issues, the researcher divided the training class into two groups. One half of the class received a handout with a scenario describing a common sexual communication mistake. The scenario described a man avoiding sexual communication with his girlfriend because he was not confident in his ability to discuss a sexual problem. In this case, the man remained unhappy in the relationship rather than communicating his sexual needs and desires with his partner. The other half of the class received a handout with a similar scenario. In this case, it was a woman who lacked the communication skills to discuss her sexual needs and 
desires with her partner. Working in small groups of 4-5, participants applied the knowledge learned from the lecture and brainstormed various ways that the man or woman in each scenario could have resolved the issue with effective communication. The researcher provided feedback to each of the small groups.

Motivation. An activity was conducted to motivate students to apply the training material to real life situations. First, participants were asked to think about a recent situation in which they witnessed or personally experienced some form of sexual communication. Due to the nature of the topic, no one was asked to share their situation with the class. Instead, the researcher asked participants to write down how they could effectively resolve the situation. The goal of this activity was to motivate students to apply the communication skills learned to potential future behaviors.

Time 2. The second data collection took place immediately following the final training session for the treatment and comparison group. The post-test questionnaire included the same measures as the pre-test assessing humor orientation, humor style, cognitive learning, selfefficacy, motivation, and humor use.

Two week Follow-up. To determine the effects of the humor communication skills training after two weeks, in addition to the post-test, participants in the treatment and comparison group also completed a questionnaire approximately two weeks after the final skills training session.. Once again, the questionnaire measured humor orientation, humor style, cognitive learning, self-efficacy, motivation, and humor use.

\section{Data Analysis Plan}

First, Pearson correlations were conducted to better understand relationships between variables in the study at baseline, post training, and at a two week follow-up, for the treatment 
and comparison group. Hypotheses one through six predicted (a) differences between the treatment and comparison group on humor style, cognitive learning, self-efficacy, motivation, and humor use, and (b) changes in scores from the pre-test to the post-test for the treatment group. Analysis of covariance (ANCOVA) with humor orientation as the covariate was used to assess differences between treatment and comparison group scores at the post-test. Additionally, repeated measures ANCOVA was used to assess potential changes in variable scores from the pre-test to the post-test for the treatment and comparison group.

Research question one asked how the humor communication skills training program would affect humor style, cognitive learning, self-efficacy, motivation, and humor use two weeks after the training program. ANCOVA with humor orientation as the covariate was used to assess differences between training types at the 2 week follow-up on each of the dependent variables. Additionally, repeated measures ANCOVA was used to assess changes in scores from the posttest to the 2 week follow-up measure for the treatment and comparison group.

\section{Summary}

This chapter described the methodology used in this dissertation. Specifically, detailed descriptions were provided concerning the study design, participants and procedures, and instruments including humor communication skills training (treatment group) and sexual communication skills training (comparison group). The data analysis methods were also outlined in this chapter. These methods were designed to evaluate the effects of a humor communication skills program on humor style, cognitive learning, self-efficacy, motivation, and humor use. The next chapter describes the results of each hypothesis and the research question. 


\section{Chapter Three}

\section{Results}

This study applied Social Cognitive Theory (Bandura, 1986; 2001) to explore the effects of humor communication skills training on humor style, cognitive learning, self-efficacy, motivation, and self-reported positive/negative humor use. Specifically, differences between the treatment group (i.e., humor communication skills training), and the comparison group (i.e., sexual communication skills training) were examined to gain a deeper understanding of the role of humor communication skills training in the interpersonal communication context. This chapter will explain preliminary data analyses, participant mortality, and results of each hypothesis and the research question.

\section{Preliminary Data Analyses}

Preliminary analyses were conducted to examine differences that could potentially confound relationships explored in the study. First, all variables were assessed for the treatment and comparison group at three points in time: baseline, post-training, and a 2 week follow-up. Generally, results of two-tailed Pearson correlations revealed that for the treatment and comparison group, humor orientation was positively related with pro-social humor style (i.e., affiliative and self-enhancing humor), self-efficacy to enact positive humor, and self-reported positive humor use. These findings are consistent with previous research which suggests that the relationships between $\mathrm{HO}$ and other positive aspects of humor may be evident because $\mathrm{HO}$ involves the predisposition to enact positive humor across various situations and contexts (e.g., Booth-Butterfield \& Booth-Butterfield, 1991, Martin et al., 2003). Results of two-tailed Pearson correlations for the treatment and comparison group at baseline, post-training, and a 2 week follow-up are reported in Tables 1-6. 
Table 1: Treatment Group - Two-tailed Pearson Correlations at Baseline

\begin{tabular}{|c|c|c|c|c|c|c|c|c|c|c|c|c|}
\hline Variable & 1 & 2 & 3 & 4 & 5 & 6 & 7 & 8 & 9 & 10 & 11 & 12 \\
\hline 1. Humor Orientation & -- & & & & & & & & & & & \\
\hline 2. Affiliative Humor & $.71 * *$ & -- & & & & & & & & & & \\
\hline 3. Self-enhancing Humor & $.38 * *$ & $.43 * *$ & -- & & & & & & & & & \\
\hline 4. Aggressive Humor & .17 & $.18 *$ & .15 & -- & & & & & & & & \\
\hline 5. Self-defeating Humor & -.02 & -.06 & .15 & $.26^{*}$ & -- & & & & & & & \\
\hline 6. Self-efficacy Positive & $.58 * *$ & $.61 * *$ & $.50 * *$ & $.22 *$ & .13 & -- & & & & & & \\
\hline 7. Self-efficacy Negative & .01 & .09 & .14 & $-.34 * *$ & $-.23 *$ & $.23^{*}$ & -- & & & & & \\
\hline 8. Motivation Positive & $.18 *$ & $.23 * *$ & $.33 * *$ & .01 & $.16^{*}$ & $.23 *$ & $.26^{*}$ & -- & & & & \\
\hline 9. Motivation Negative & .06 & .03 & $.20 *$ & $-.25 *$ & -.07 & .13 & $.43^{* *}$ & $.58 * *$ & -- & & & \\
\hline 10. Humor Use Positive & $.63 * *$ & $.53 * *$ & $.46 * *$ & $.16^{*}$ & .04 & $.64 * *$ & $.23 *$ & $.24 *$ & .11 & -- & & \\
\hline 11. Humor Use Negative & -.11 & $-.21 *$ & .01 & $-.44 * *$ & $-.31 * *$ & -.01 & $.46 * *$ & -.03 & $.25^{*}$ & .06 & -- & \\
\hline 12. Cognitive Learning & .14 & $.24 *$ & $.18 *$ & -.03 & $-.18 *$ & .10 & .09 & .12 & .05 & .001 & -.07 & -- \\
\hline
\end{tabular}

Note. $* p<.05 . * * p<.001$.

Table 2: Comparison Group - Two-tailed Pearson Correlations at Baseline

\begin{tabular}{|c|c|c|c|c|c|c|c|c|c|c|c|c|}
\hline Variable & 1 & 2 & 3 & 4 & 5 & 6 & 7 & 8 & 9 & 10 & 11 & 12 \\
\hline 1. Humor Orientation & -- & & & & & & & & & & & \\
\hline 2. Affiliative Humor & $.76 * *$ & -- & & & & & & & & & & \\
\hline 3. Self-enhancing Humor & $.40 * *$ & $.34 * *$ & -- & & & & & & & & & \\
\hline 4. Aggressive Humor & -.10 & -.06 & .001 & -- & & & & & & & & \\
\hline 5. Self-defeating Humor & -.06 & .03 & $.21 *$ & $.18^{*}$ & -- & & & & & & & \\
\hline 6. Self-efficacy Positive & $.62 * *$ & $.49 * *$ & $.56 * *$ & .02 & $.17 *$ & -- & & & & & & \\
\hline 7. Self-efficacy Negative & $.32 * *$ & $.24 *$ & $.22 *$ & $-.25 *$ & $-.02 *$ & $.48 * *$ & -- & & & & & \\
\hline 8. Motivation Positive & .08 & .16 & $.23^{*}$ & $-.21 *$ & .14 & $.25^{*}$ & $.24 *$ & -- & & & & \\
\hline 9. Motivation Negative & .10 & .09 & .04 & $-.39 * *$ & .01 & .07 & $.29 * *$ & $.63 * *$ & -- & & & \\
\hline 10. Humor Use Positive & $.62 * *$ & $.59 * *$ & $.36^{* *}$ & -.09 & .09 & $.61 * *$ & $.41 * *$ & $.24 *$ & .15 & -- & & \\
\hline 11. Humor Use Negative & .11 & .07 & .14 & $-.55 * *$ & -.10 & $.21 *$ & $.49 * *$ & $.37 * *$ & $.44 * *$ & $.20 *$ & -- & \\
\hline 12. Cognitive Learning & .12 & .13 & .06 & .02 & $-.16^{*}$ & .03 & .003 & .02 & -.10 & .03 & -.06 & -- \\
\hline
\end{tabular}


Table 3: Treatment Group - Two-tailed Pearson Correlations Post-Training

\begin{tabular}{|c|c|c|c|c|c|c|c|c|c|c|c|c|}
\hline Variable & 1 & 2 & 3 & 4 & 5 & 6 & 7 & 8 & 9 & 10 & 11 & 12 \\
\hline 1. Humor Orientation & -- & & & & & & & & & & & \\
\hline 2. Affiliative Humor & $.71 * *$ & -- & & & & & & & & & & \\
\hline 3. Self-enhancing Humor & $.48 * *$ & $.51 * *$ & -- & & & & & & & & & \\
\hline 4. Aggressive Humor & .22 & $.17 *$ & .11 & -- & & & & & & & & \\
\hline 5. Self-defeating Humor & $-.18 *$ & $-.38 * *$ & .03 & $.20 *$ & -- & & & & & & & \\
\hline 6. Self-efficacy Positive & $.45^{* *}$ & $.34 * *$ & $.44 * *$ & $-.01 *$ & .001 & -- & & & & & & \\
\hline 7. Self-efficacy Negative & .13 & .08 & $.22 *$ & $-.29 * *$ & $-.19 *$ & $.48 * *$ & -- & & & & & \\
\hline 8. Motivation Positive & $.25 * *$ & $.17 *$ & $.19 *$ & -.09 & .02 & $.16^{*}$ & $.22 *$ & -- & & & & \\
\hline 9. Motivation Negative & .06 & .05 & .11 & $-.33 * *$ & -.05 & .15 & $.24 *$ & $.58 * *$ & -- & & & \\
\hline 10. Humor Use Positive & $.46^{* *}$ & $.32 * *$ & $.31 * *$ & .01 & -.07 & $.57 * *$ & $.21 *$ & $.35^{*}$ & .14 & -- & & \\
\hline 11. Humor Use Negative & -.02 & $-.16 *$ & .04 & $-.59 * *$ & $-.18 *$ & $.19^{*}$ & $.48 * *$ & $.18^{*}$ & $.48 * *$ & $.24 *$ & -- & \\
\hline 12. Cognitive Learning & $.20 *$ & $.31 * *$ & .13 & -.01 & $-.24 *$ & .14 & .001 & .12 & .06 & -.03 & -.01 & -- \\
\hline
\end{tabular}

Note. $* p<.05 . * * p<.001$.

Table 4: Comparison Group - Two-tailed Pearson Correlations Post-Training

\begin{tabular}{|c|c|c|c|c|c|c|c|c|c|c|c|c|}
\hline Variable & 1 & 2 & 3 & 4 & 5 & 6 & 7 & 8 & 9 & 10 & 11 & 12 \\
\hline 1. Humor Orientation & -- & & & & & & & & & & & \\
\hline 2. Affiliative Humor & $.80 * *$ & -- & & & & & & & & & & \\
\hline 3. Self-enhancing Humor & $.47 * *$ & $.41 * *$ & -- & & & & & & & & & \\
\hline 4. Aggressive Humor & -.10 & -.10 & .04 & -- & & & & & & & & \\
\hline 5. Self-defeating Humor & -.06 & -.10 & .06 & $.24 *$ & -- & & & & & & & \\
\hline 6. Self-efficacy Positive & $.52 * *$ & $.52 * *$ & $.45^{* *}$ & -.05 & .05 & -- & & & & & & \\
\hline 7. Self-efficacy Negative & $.19 *$ & $.25^{*}$ & .10 & -.17 & -.09 & $.38 * *$ & -- & & & & & \\
\hline 8. Motivation Positive & $.28 * *$ & $.31 * *$ & $.17 *$ & $-.32 * *$ & .01 & $.30 * *$ & $.20^{*}$ & -- & & & & \\
\hline 9. Motivation Negative & $.28 *$ & $.25^{*}$ & $.20 *$ & $-.32 * *$ & -.01 & $.18 *$ & $.23^{*}$ & $.73 * *$ & -- & & & \\
\hline 10. Humor Use Positive & $.46 * *$ & $.51 * *$ & $.36 * *$ & -.12 & -.01 & $.45^{* *}$ & $.23^{*}$ & $.53 * *$ & $.37 * *$ & -- & & \\
\hline 11. Humor Use Negative & $.23^{*}$ & $.25^{*}$ & $.16^{*}$ & $-.42 * *$ & $-.17 *$ & $.35 * *$ & $.29 *$ & $.48 * *$ & $.48 * *$ & $.54 * *$ & -- & \\
\hline 12. Cognitive Learning & $.27 *$ & $.29 * *$ & .11 & .03 & $-.21 *$ & .12 & $.28^{*}$ & .13 & .15 & .12 & .02 & -- \\
\hline
\end{tabular}


Table 5: Treatment Group - Two-tailed Pearson Correlations 2 Week Follow-up

\begin{tabular}{|c|c|c|c|c|c|c|c|c|c|c|c|c|}
\hline Variable & 1 & 2 & 3 & 4 & 5 & 6 & 7 & 8 & 9 & 10 & 11 & 12 \\
\hline 1. Humor Orientation & -- & & & & & & & & & & & \\
\hline 2. Affiliative Humor & $.69 * *$ & -- & & & & & & & & & & \\
\hline 3. Self-enhancing Humor & $.49 * *$ & $.50 * *$ & -- & & & & & & & & & \\
\hline 4. Aggressive Humor & $.25^{*}$ & $.20 *$ & .17 & -- & & & & & & & & \\
\hline 5. Self-defeating Humor & $-.29 *$ & $-.37 * *$ & -.11 & .01 & -- & & & & & & & \\
\hline 6. Self-efficacy Positive & $.30 *$ & $.26^{*}$ & $.29 * *$ & -.03 & -.02 & -- & & & & & & \\
\hline 7. Self-efficacy Negative & .02 & -.01 & .17 & $-.37 * *$ & .01 & $.63 * *$ & -- & & & & & \\
\hline 8. Motivation Positive & $.29 *$ & $.26 *$ & $.26^{*}$ & -.11 & .08 & $.23^{*}$ & $.23 *$ & -- & & & & \\
\hline 9. Motivation Negative & .15 & .03 & $.23 *$ & $-.29 *$ & .09 & .13 & $.26^{*}$ & $.67 * *$ & -- & & & \\
\hline 10. Humor Use Positive & $.46^{* *}$ & $.47 * *$ & $.29 * *$ & .13 & -.12 & $.41 * *$ & $.28 *$ & $.35 *$ & $.20 *$ & -- & & \\
\hline 11. Humor Use Negative & .02 & $.30 *$ & .07 & $-.56 * *$ & .001 & $.22 *$ & $.51 * *$ & $.20 *$ & $.45^{* *}$ & $.43 * *$ & -- & \\
\hline 12. Cognitive Learning & .12 & .15 & .09 & -.03 & $-.20 *$ & .12 & .11 & .09 & .13 & $.23 *$ & .10 & -- \\
\hline
\end{tabular}
Note. $* p<.05 . * * p<.001$.

Table 6: Comparison Group - Two-tailed Pearson Correlations 2 Week Follow-up

\begin{tabular}{|c|c|c|c|c|c|c|c|c|c|c|c|c|}
\hline Variable & 1 & 2 & 3 & 4 & 5 & 6 & 7 & 8 & 9 & 10 & 11 & 12 \\
\hline 1. Humor Orientation & -- & & & & & & & & & & & \\
\hline 2. Affiliative Humor & $.72 * *$ & -- & & & & & & & & & & \\
\hline 3. Self-enhancing Humor & $.55 * *$ & $.49 * *$ & -- & & & & & & & & & \\
\hline 4. Aggressive Humor & -.09 & -.10 & -.11 & -- & & & & & & & & \\
\hline 5. Self-defeating Humor & -.01 & -.04 & .13 & $.25^{*}$ & -- & & & & & & & \\
\hline 6. Self-efficacy Positive & $.28 *$ & $.26^{*}$ & $.21 *$ & -.09 & .06 & -- & & & & & & \\
\hline 7. Self-efficacy Negative & $.23 *$ & .17 & $.21 *$ & $-.28 *$ & -.08 & $68 * *$ & -- & & & & & \\
\hline 8. Motivation Positive & $.25 * *$ & .19 & $.22 *$ & -.11 & .07 & $.31 *$ & $.30 *$ & -- & & & & \\
\hline 9. Motivation Negative & $.22 *$ & .13 & .08 & $-.24 *$ & .09 & $.38 * *$ & $.44 * *$ & $.53 * *$ & -- & & & \\
\hline 10. Humor Use Positive & $.40 * *$ & $.39 * *$ & $.48 * *$ & -.17 & -.01 & $.52 * *$ & $.42 * *$ & $.33 *$ & $.20 *$ & -- & & \\
\hline 11. Humor Use Negative & .16 & .06 & .14 & $-.54 * *$ & -.13 & $.34 * *$ & $.45 * *$ & $.25^{*}$ & $.37 * *$ & $.46 * *$ & -- & \\
\hline 12. Cognitive Learning & .09 & .10 & .07 & .17 & -.02 & .06 & .11 & -.02 & .04 & .03 & .04 & -- \\
\hline
\end{tabular}


To check equivalence in groups, independent samples $t$-tests were conducted. Results indicated that there were no statistically significant differences in baseline scores for any of the variables between the treatment and comparison group (see Table 7). Therefore, the groups were homogenous from the start and any differences observed between the groups could be attributed to the manipulation.

Table 7: Treatment and Comparison Group Baseline Statistics. Mean, Standard Deviation in Parentheses.

\begin{tabular}{|llllrl|}
\hline \multicolumn{7}{c|}{ Baseline Statistics } \\
\hline Variable & Treatment Group & Comparison Group & $\boldsymbol{d} \boldsymbol{f}$ & $\boldsymbol{t}$-value & $\boldsymbol{p}$ \\
\hline 1. Humor Orientation & $3.86(.51)$ & $3.85(.55)$ & 299 & -.36 & .72 \\
2. Affiliative Humor & $4.22(.48)$ & $4.23(.53)$ & 299 & -.08 & .94 \\
3. Self-enhancing Humor & $3.55(.62)$ & $3.55(.69)$ & 299 & 1.26 & .21 \\
4. Aggressive Humor & $2.84(.58)$ & $2.80(.56)$ & 299 & .70 & .49 \\
5. Self-defeating humor & $2.62(.68)$ & $2.67(.84)$ & 299 & -.63 & .53 \\
6. Cognitive Learning & $.54(.21)$ & $.55(.19)$ & 299 & -.51 & .61 \\
7. Self-efficacy Positive & $6.83(1.59)$ & $6.98(1.50)$ & 299 & -.83 & .41 \\
8. Self-efficacy Negative & $6.52(1.78)$ & $6.44(2.04)$ & 299 & .35 & .73 \\
9. Motivation Positive & $2.87(.60)$ & $2.88(.63)$ & 299 & -.01 & .99 \\
10. Motivation Negative & $2.73(.66)$ & $2.80(.73)$ & 299 & -.88 & .38 \\
11. Humor Use Positive & $4.16(.66)$ & $4.26(.70)$ & 299 & -1.30 & .20 \\
12. Humor Use Negative & $3.41(.91)$ & $3.50(.85)$ & 299 & -.87 & .38 \\
\hline
\end{tabular}

Independent samples $t$-tests were also conducted to test for potential sex differences in study variables for the treatment and comparison group. Consistent with previous research (e.g., Cann et al., 2009; Martin et al., 2003), results generally indicated that men in the treatment and comparison group reported having a more aggressive humor style than women at baseline, posttraining, and a two week follow-up. Additionally, men in the treatment and comparison group reported greater self-efficacy to enact positive humor than women at the baseline data collection. Results for the treatment group are reported in Table 8 and results for the comparison group are reported in Table 9. 
Table 8: Treatment Group Sex Differences. Mean, Standard Deviation in Parentheses.

\begin{tabular}{|c|c|c|c|c|c|c|}
\hline Variable & Time & Men & Women & $d f$ & $t$-value & $p$ \\
\hline \multirow[t]{3}{*}{ 1. Humor Orientation } & Pre-test & $3.88(.44)$ & $3.78(.56)$ & 150 & 1.30 & .20 \\
\hline & Post-test & $3.85(.47)$ & $3.78(.63)$ & 150 & .75 & .45 \\
\hline & Follow-up & $3.77(.55)$ & $3.81(.58)$ & 105 & -.40 & .69 \\
\hline \multirow[t]{3}{*}{ 2. Affiliative Humor } & Pre-test & $4.23(.45)$ & $4.22(.51)$ & 150 & .09 & .93 \\
\hline & Post-test & $4.03(.60)$ & $4.11(.54)$ & 150 & -.91 & .37 \\
\hline & Follow-up & $3.93(.63)$ & $4.06(.60)$ & 106 & -1.12 & .26 \\
\hline \multirow[t]{3}{*}{ 3. Self-enhancing Humor } & Pre-test & $3.54(.52)$ & $3.55(.70)$ & 150 & -.06 & .95 \\
\hline & Post-test & $3.63(.53)$ & $3.64(.68)$ & 150 & -.08 & .94 \\
\hline & Follow-up & $3.53(.53)$ & $3.57(.55)$ & 105 & -.38 & .70 \\
\hline \multirow[t]{3}{*}{ 4. Aggressive Humor } & Pre-test & $2.98(.53)$ & $2.71(.55)$ & 150 & $3.14 *$ & .002 \\
\hline & Post-test & $3.10(.59)$ & $2.76(.59)$ & 150 & $3.61^{* *}$ & .000 \\
\hline & Follow-up & $3.12(.54)$ & $2.83(.53)$ & 106 & $2.77^{*}$ & .01 \\
\hline \multirow[t]{3}{*}{ 5. Self-defeating humor } & Pre-test & $2.66(.62)$ & $2.58(.73)$ & 150 & .72 & .47 \\
\hline & Post-test & $2.69(.69)$ & $2.63(.68)$ & 150 & .66 & .51 \\
\hline & Follow-up & $2.76(.57)$ & $2.57(.62)$ & 105 & 1.62 & .11 \\
\hline \multirow{3}{*}{ 6. Cognitive Learning } & Pre-test & $.51(.22)$ & $.57(.20)$ & 150 & -1.59 & .11 \\
\hline & Post-test & $.72(.24)$ & $.82(.17)$ & 150 & $-2.88 *$ & .01 \\
\hline & Follow-up & $.68(.27)$ & $.74(.22)$ & 105 & -1.34 & .19 \\
\hline \multirow[t]{3}{*}{ 7. Self-efficacy Positive } & Pre-test & $7.16(1.34)$ & $6.52(1.75)$ & 150 & $2.53^{*}$ & .01 \\
\hline & Post-test & $7.40(1.25)$ & $7.21(1.55)$ & 150 & .84 & .40 \\
\hline & Follow-up & $7.08(1.59)$ & $6.70(1.83)$ & 106 & 1.16 & .25 \\
\hline \multirow[t]{3}{*}{ 8. Self-efficacy Negative } & Pre-test & $6.38(1.64)$ & $6.65(1.92)$ & 150 & -.94 & .35 \\
\hline & Post-test & $6.85(1.70)$ & $6.84(1.77)$ & 150 & .06 & .95 \\
\hline & Follow-up & $6.27(2.08)$ & $6.42(1.90)$ & 106 & -.40 & .69 \\
\hline \multirow[t]{3}{*}{ 9. Motivation Positive } & Pre-test & $2.89(.63)$ & $2.86(.57)$ & 150 & .31 & .76 \\
\hline & Post-test & $3.00(.62)$ & $2.93(.61)$ & 150 & .68 & .50 \\
\hline & Follow-up & $2.72(.55)$ & $2.90(.52)$ & 106 & -1.83 & .07 \\
\hline \multirow[t]{3}{*}{ 10. Motivation Negative } & Pre-test & $2.65(.75)$ & $2.80(.56)$ & 150 & -1.46 & .15 \\
\hline & Post-test & $2.76(.79)$ & $2.75(.67)$ & 150 & .09 & .93 \\
\hline & Follow-up & $2.60(.73)$ & $2.75(.54)$ & 106 & -1.18 & .24 \\
\hline \multirow[t]{3}{*}{ 11. Humor Use Positive } & Pre-test & $4.21(.53)$ & $4.10(.76)$ & 150 & 1.03 & .31 \\
\hline & Post-test & $4.20(.65)$ & $4.04(.69)$ & 150 & 1.46 & .15 \\
\hline & Follow-up & $3.77(.89)$ & $4.12(.75)$ & 106 & $-2.23 *$ & .03 \\
\hline \multirow[t]{3}{*}{ 12. Humor Use Negative } & Pre-test & $3.24(.94)$ & $3.26(.86)$ & 150 & -2.30 & .20 \\
\hline & Post-test & $3.36(.89)$ & $3.51(.95)$ & 150 & -1.05 & .30 \\
\hline & Follow-up & $3.21(1.07)$ & $3.47(.89)$ & 106 & -1.05 & .17 \\
\hline
\end{tabular}

Note. ${ }^{*} p<.05 .{ }^{* *} p<.001$. 
Table 9: Comparison Group Sex Differences. Mean, Standard Deviation in Parentheses.

\begin{tabular}{|c|c|c|c|c|c|c|}
\hline Variable & Time & Men & Women & $d f$ & $t$-value & $p$ \\
\hline \multirow[t]{3}{*}{ 1. Humor Orientation } & Pre-test & $3.82(.48)$ & $3.88(.62)$ & 150 & -.68 & .50 \\
\hline & Post-test & $3.78(.55)$ & $3.86(.62)$ & 150 & -.76 & .44 \\
\hline & Follow-up & $3.70(.59)$ & $3.82(.53)$ & 105 & -1.02 & .31 \\
\hline \multirow[t]{3}{*}{ 2. Affiliative Humor } & Pre-test & $4.14(.54)$ & $4.20(.55)$ & 150 & -1.17 & .06 \\
\hline & Post-test & $3.97(.59)$ & $3.99(.64)$ & 150 & -1.26 & .09 \\
\hline & Follow-up & $3.88(.64)$ & $3.99(.65)$ & 106 & -.82 & .42 \\
\hline \multirow[t]{3}{*}{ 3. Self-enhancing Humor } & Pre-test & $3.45(.63)$ & $3.46(.76)$ & 150 & -.09 & .93 \\
\hline & Post-test & $3.47(.64)$ & $3.50(.72)$ & 150 & -.18 & .86 \\
\hline & Follow-up & $3.39(.69)$ & $3.43(.79)$ & 105 & -.25 & .81 \\
\hline \multirow[t]{3}{*}{ 4. Aggressive Humor } & Pre-test & $2.96(.53)$ & $2.61(.54)$ & 150 & $3.99 * *$ & .000 \\
\hline & Post-test & $3.01(.53)$ & $2.66(.63)$ & 150 & $3.64 * *$ & .000 \\
\hline & Follow-up & $3.02(.51)$ & $2.67(.58)$ & 106 & $3.22 *$ & .002 \\
\hline \multirow[t]{3}{*}{ 5. Self-defeating humor } & Pre-test & $2.73(.62)$ & $2.60(.72)$ & 150 & .20 & .23 \\
\hline & Post-test & $2.78(.64)$ & $2.72(.70)$ & 150 & .46 & .57 \\
\hline & Follow-up & $2.75(.67)$ & $2.72(.72)$ & 105 & .24 & .81 \\
\hline \multirow[t]{3}{*}{ 6. Cognitive Learning } & Pre-test & $.55(.20)$ & $.56(.19)$ & 150 & -.37 & .72 \\
\hline & Post-test & $.49(.24)$ & $.55(.19)$ & 150 & -1.78 & .08 \\
\hline & Follow-up & $.38(.29)$ & $.25(.17)$ & 105 & -.41 & .68 \\
\hline \multirow[t]{3}{*}{ 7. Self-efficacy Positive } & Pre-test & $7.25(1.36)$ & $6.68(1.59)$ & 150 & $2.35^{*}$ & .02 \\
\hline & Post-test & $7.14(1.33)$ & $6.80(1.73)$ & 150 & 1.34 & .18 \\
\hline & Follow-up & $6.45(1.45)$ & $6.18(1.78)$ & 106 & .85 & .40 \\
\hline \multirow[t]{3}{*}{ 8. Self-efficacy Negative } & Pre-test & $6.50(1.96)$ & $6.32(2.15)$ & 150 & .33 & .74 \\
\hline & Post-test & $6.54(1.83)$ & $6.45(2.20)$ & 150 & .25 & .80 \\
\hline & Follow-up & $5.58(1.83)$ & $5.94(1.90)$ & 106 & -.97 & .34 \\
\hline \multirow[t]{3}{*}{ 9. Motivation Positive } & Pre-test & $2.83(.64)$ & $2.92(.40)$ & 150 & -.83 & .41 \\
\hline & Post-test & $2.90(.58)$ & $2.85(.63)$ & 150 & -2.03 & .05 \\
\hline & Follow-up & $2.84(.28)$ & $2.98(.62)$ & 106 & -1.16 & .25 \\
\hline \multirow[t]{3}{*}{ 10. Motivation Negative } & Pre-test & $2.60(.72)$ & $2.70(.68)$ & 150 & -1.60 & .25 \\
\hline & Post-test & $2.68(.77)$ & $2.72(.72)$ & 150 & -1.34 & .46 \\
\hline & Follow-up & $2.62(.71)$ & $2.67(.59)$ & 106 & -1.18 & .19 \\
\hline \multirow[t]{3}{*}{ 11. Humor Use Positive } & Pre-test & $4.25(.66)$ & $4.26(.69)$ & 150 & -.06 & .96 \\
\hline & Post-test & $4.22(.68)$ & $4.13(.89)$ & 150 & .70 & .48 \\
\hline & Follow-up & $4.07(.80)$ & $3.85(.82)$ & 106 & 1.40 & .16 \\
\hline \multirow[t]{3}{*}{ 12. Humor Use Negative } & Pre-test & $3.44(.82)$ & $3.57(.89)$ & 150 & -.95 & .35 \\
\hline & Post-test & $3.56(.93)$ & $3.63(1.01)$ & 150 & -.46 & .64 \\
\hline & Follow-up & $3.56(.96)$ & $3.56(.78)$ & 106 & -.73 &. .47 \\
\hline
\end{tabular}

Note. ${ }^{*} p<.05 . * * p<.001$. 
Understanding Participant Mortality. To examine the possibility that the initial sample and final sample may have differed based on individual characteristics, independent samples $t$-tests were conducted assessing potential differences on the measures included in the study. Given the smaller mortality rate between Time $2(n=301)$ and Time $3(n=210)$, analyses focused on differences between participants who completed just the pre-test at Time 1 $(n=50)$ and those who completed all three data collections $(n=210)$. Results of independent samples $t$-tests revealed that there were no statistically significant differences between those who only completed the pre-test and those who completed all three data collections on any of the variables in the study except positive humor use. Those who only completed the pre-test reported using more positive humor $(M=4.45, S D=.61)$ than those who completed all three data collections $(M=4.20, S D=.66, t(352)=-2.53, p=.01)$. Consequently, participants in this sample who completed all three data collections reported that, overall, they communicate less positive humor than those participants who only completed the pre-test.

\section{Test of Hypotheses}

Hypothesis 1. Hypothesis 1 predicted that humor communication skills training would affect humor styles such that individuals in the treatment group would report (a) more pro-social humor (i.e., affiliative and self-enhancing) than those in the comparison group and (b) an increase in pro-social humor scores from the pre-test to the post-test. ANCOVA was used to test for differences between the training types on each of the pro-social humor styles. Using a covariate can (a) reduce error variance, (b) account for any pre-existing mean group difference on the covariate, (c) account for the relationship between the covariate and the dependent variable, and (d) provide a more accurate and less biased estimate of the treatment effect (Frey, Botan, \& Kreps, 2000). Additionally, repeated measures ANCOVA was used to test for changes in scores for each of the dependent variables from the pre-test to the post-test. 
Affiliative humor. ANCOVA was conducted with affiliative humor as the dependent variable, training type as the fixed factor, and humor orientation as the covariate. The Levene's test of equality of error variances was not statistically significant $(p=.59)$, assuring homogeneity (i.e., groups had approximately equal variances). Results indicated no statistically significant differences in affiliative humor by training type when controlling for humor orientation $(F(1$, 298) $=.05, p=.82, \eta_{\mathrm{p}}{ }^{2}=0.00$, observed power $=.06$, treatment group $(M=4.08, S D=.25)$, comparison group $(M=4.15, S D=.25)$.

Although there were no statistically significant differences between the training groups on affiliative humor, results of repeated measures ANCOVA indicated a statistically significant increase in affiliative humor scores for the treatment group from the pre-test to the post-test ( $F$ $(1,150)=18.31, p<.001, \eta_{\mathrm{p}}{ }^{2}=.12$, observed power $=.99$, pre-test $(M=3.47, S D=.38)$, posttest $(M=4.20, S D=.25)$. However, there was also a statistically significant increase in affiliative humor scores for the comparison group from the pre-test to the post-test $(F(1,146)=$ $19.09, p<.001, \eta_{\mathrm{p}}{ }^{2}=.12$, observed power $=.99$, pre-test $(M=4.07, S D=.24)$, post-test $(M=$ $4.15, S D=.25$ ). Therefore, although there were no statistically significant differences between the training types on affiliative humor at the post-test, individuals in the treatment and comparison groups reported increases in affiliative humor from the pre-test to the post-test.

Self-enhancing humor. ANCOVA was conducted with self-enhancing humor as the dependent variable, training type as the fixed factor, and humor orientation as the covariate. The Levene's test of equality of error variances was not statistically significant $(p=.53)$, assuring homogeneity (i.e., groups had approximately equal variances). Results indicated statistically significant differences in self-enhancing humor by training type when controlling for humor orientation $\left(F(1,298)=5.72, p=.02, \eta_{\mathrm{p}}^{2}=.019\right.$, observed power $\left.=.67\right)$. Specifically, 
participants in the humor skills training group reported using more self-enhancing humor $(M=$ $3.64, S D=.37)$ than those in the comparison group $(M=3.48, S D=.37)$.

Results of repeated measures ANCOVA also indicated a statistically significant increase in self-enhancing humor scores for the treatment group from the pre-test to the post-test $(F$ (1, $150)=6.26, p=.02, \eta_{\mathrm{p}}{ }^{2}=.04$, observed power $=.70$, pre-test $(M=3.55, S D=.37)$, post-test $(M$ $=3.64, S D=.35)$. However, there was not a statistically significant change in self-enhancing humor scores for the comparison group from the pre-test to the post-test $(F(1,146)=.78, p=$ $.38, \eta_{\mathrm{p}}{ }^{2}=.005$, observed power $=.14$, pre-test $(M=3.45, S D=.42)$, post-test $(M=3.48, S D=$ .37). Therefore, individuals in the treatment group reported more self-enhancing humor on the post-test measure and an improvement in self-enhancing humor from the pre-test to the post-test. Overall, hypothesis one was partially supported as the humor communication skills training program positively impacted self-enhancing humor but not affiliative humor.

Hypothesis 2. Hypothesis 2 predicted that humor communication skills training would affect humor styles such that individuals in the treatment group would report (a) less anti-social humor (i.e., aggressive and self-defeating humor) than those in the comparison group, and (b) a decrease in anti-social humor scores from the pre-test to the post-test.

Aggressive humor. ANCOVA was conducted with aggressive humor as the dependent variable, training type as the fixed factor, and humor orientation as the covariate. The Levene's test of equality of error variances was not statistically significant $(p=.79)$, assuring homogeneity (i.e., groups had approximately equal variances). However, results indicated no statistically significant differences in aggressive humor by training type when controlling for humor orientation $\left(F(1,298)=1.26, p=.26, \eta_{\mathrm{p}}{ }^{2}=.004\right.$, observed power $=.20$, treatment group $(M=$ $2.85, S D=.40)$, comparison group $(M=2.92, S D=.40)$ 
Results of repeated measures ANCOVA indicated that there was not a statistically significant change in aggressive humor scores for the treatment group from the pre-test to the post-test $\left(F(1,149)=4.50, p=.06, \eta_{\mathrm{p}}^{2}=.03\right.$, observed power $=.56$; pre-test $(M=2.90, S D=$ $.39)$, post-test $(M=2.85, S D=.40)$. There was also not a statistically significant change in aggressive humor scores for the comparison group from the pre-test to the post-test $(F(1,146)=$ $2.07, p=.15, \eta_{\mathrm{p}}{ }^{2}=.02$, observed power $=.30$, pre-test $(M=2.80, S D=.37)$, post-test $(M=2.92$, $S D=.40)$. Therefore, there were no statistically significant differences between the training types on aggressive humor at the post-test, and individuals in the humor skills training group did not report a significant change in aggressive humor from the pre-test to the post-test.

Self-defeating humor. ANCOVA was conducted with self-defeating humor as the dependent variable, training type as the fixed factor, and humor orientation as the covariate. The Levene's test of equality of error variances was not statistically significant $(p=.82)$, assuring homogeneity (i.e., groups had approximately equal variances). However, results indicated no statistically significant differences in self-defeating humor by training type when controlling for humor orientation $\left(F(1,298)=1.32, p=.25, \eta_{\mathrm{p}}{ }^{2}=.004\right.$, observed power $=.21$, treatment group $(M=2.67, S D=.43)$, comparison group $(M=2.75, S D=.44)$.

Results of repeated measures ANCOVA indicated that there was not a statistically significant change in self-defeating humor scores for the treatment group from the pre-test to the post-test $\left(F(1,149)=1.11, p=.30, \eta_{\mathrm{p}}{ }^{2}=.007\right.$, observed power $=.18$; pre-test $(M=2.62, S D=$ $.44)$, post-test $(M=2.67, S D=.43)$. There was also not a statistically significant change in selfdefeating humor for the comparison group from the pre-test to the post-test $(F(1,146)=3.77, p$ $=.06, \eta_{\mathrm{p}}^{2}=.03$, observed power $=.49$, pre-test $(M=2.67, S D=.44)$, post-test $(M=2.63, S D=$ .44). Therefore, there were no statistically significant differences between the training types on 
self-defeating humor at the post-test, and individuals in the humor skills training group did not report a significant change in self-defeating humor from the pre-test to the post-test. Hypothesis two was not supported.

Hypothesis 3. Hypothesis 3 predicted that humor communication skills training would affect cognitive learning such that individuals in the treatment group would report (a) more cognitive learning than those in the comparison group, and (b) an increase in cognitive learning scores from the pre-test to the post-test measure. ANCOVA was conducted with cognitive learning as the dependent variable, training type as the fixed factor, and humor orientation as the covariate. The Levene's test of equality of error variances was not statistically significant ( $p=$ .71), assuring homogeneity (i.e., groups had approximately equal variances). As expected, results indicated statistically significant differences in cognitive learning between training types when controlling for humor orientation $\left(F(1,298)=114.86, p<.001, \eta_{\mathrm{p}}{ }^{2}=.28\right.$, observed power $=1.00$ ). Specifically, participants in the humor skills training group reported more cognitive learning $(M=.78, S D=.20)$ than did those in the comparison group $(M=6.52, S D=.21)$.

Results of repeated measures ANCOVA also indicated a statistically significant increase in cognitive learning scores for the treatment group form the pre-test to the post-test $(F(1,146)=$ $131.60, p<.001, \eta_{\mathrm{p}}{ }^{2}=.47$, observed power $=1.00 ;$ pre-test $(M=.54, S D=.21)$, post-test $(M=$ $.78, S D=.20)$. However, there was not a statistically significant change in cognitive learning scores for the comparison group $\left(F(1,146)=4.62, p=.08, \eta_{\mathrm{p}}^{2}=.03\right.$, observed power $=.57$, pretest $(M=.55, S D=.18)$, post-test $(M=.52, S D=.21)$. Therefore, individuals in the treatment group reported more cognitive learning on the post-test measure than those in the comparison group, and an improvement in cognitive learning from the pre-test to the post-test. Hypothesis three was supported. 
Hypothesis 4. Hypothesis 4 predicted that humor communication skills training would affect self-efficacy such that individuals in the treatment group would report (a) more selfefficacy to enact positive humor and to avoid the enactment of negative humor than those in the comparison group, and (b) an increase in self-efficacy scores from the pre-test to the post-test.

Self-efficacy to enact positive humor. ANCOVA was conducted with self-efficacy to enact positive humor as the dependent variable, training type as the fixed factor, and humor orientation as the covariate. The Levene's test of equality of error variances was not statistically significant ( $p=.91$ ), assuring homogeneity (i.e., groups had approximately equal variances). As expected, results indicated statistically significant differences in self-efficacy to enact positive humor between the training types when controlling for humor orientation $(F(1,298)=5.52, p=$ $.02, \eta_{\mathrm{p}}{ }^{2}=.016$, observed power $\left.=.67\right)$. Specifically, participants in the treatment group reported greater self-efficacy to enact positive humor $(M=7.32, S D=.83)$ than those in the comparison group $(M=6.70, S D=.84)$.

Results of repeated measures ANCOVA also indicated a statistically significant increase in self-efficacy to enact positive humor scores for the treatment group from the pre-test to the post-test $\left(F(1,149)=20.41, p<.001, \eta_{\mathrm{p}}{ }^{2}=.12\right.$, observed power $=.99$, pre-test $(M=6.83, S D=$ $.84)$, post-test $(M=7.32, S D=.83)$. However there was not a statistically significant change in self-efficacy to enact positive humor for the comparison group from the pre-test to the post-test $\left(F(1,146)=.001, p=.98, \eta_{\mathrm{p}}{ }^{2}=.000\right.$, observed power $=.05 ;$ pre-test $(M=6.98, S D=.78)$, posttest $(M=6.97, S D=.84)$. Therefore, individuals in the treatment group reported greater selfefficacy to enact positive humor on the post-test measure and an improvement in self-efficacy to enact positive humor from the pre-test to the post-test. 
Self-efficacy to avoid negative humor. ANCOVA was conducted with self-efficacy to avoid enacting negative humor as the dependent variable, training type as the fixed factor, and humor orientation as the covariate. The Levene's test of equality of error variances was not statistically significant $(p=.58)$, assuring homogeneity (i.e., groups had approximately equal variances). As expected, results indicated statistically significant differences in self-efficacy to avoid enacting negative humor between the training types when controlling for humor orientation $\left(F(1,298)=5.27, p=.02, \eta_{\mathrm{p}}^{2}=.03\right.$, observed power $\left.=.63\right)$. Specifically, participants in the humor skills training group reported more self-efficacy to avoid enacting negative humor $(M=6.85, S D=1.12)$ than those in the comparison group $(M=6.50, S D=$ 1.26).

Results of repeated measures ANCOVA also indicated a statistically significant increase in self-efficacy to avoid negative humor scores for the treatment group from the pre-test to the post-test $\left(F(1,149)=4.42, p=.04, \eta_{\mathrm{p}}{ }^{2}=.03\right.$, observed power $=.60$, pre-test $(M=56.52, S D=$ $1.16)$, post-test $(M=6.85, S D=1.12)$. However there was not a statistically significant change in self-efficacy for the comparison group $\left(F(1,146)=4.42, p=.40, \eta_{\mathrm{p}}{ }^{2}=.03\right.$, observed power $=$ .60 ; pre-test $(M=6.44, S D=1.27)$, post-test $(M=6.50, S D=1.26)$. Therefore, individuals in the treatment group reported greater self-efficacy to avoid negative humor on the post-test measure and an improvement in self-efficacy to avoid negative humor from the pre-test to the post-test. Hypothesis four was supported.

Hypothesis 5. Hypothesis 5 predicted that humor communication skills training would affect motivation such that individuals in the treatment group would report (a) being more motivated to enact positive humor and to avoid the enactment of negative humor than those in the comparison group, and (b) an increase in motivation scores from the pre-test to the post-test. 
Motivation to enact positive humor. ANCOVA was conducted motivation to enact positive humor as the dependent variable, training type as the fixed factor, and humor orientation as the covariate. The Levene's test of equality of error variances was not statistically significant $(p=.97)$, assuring homogeneity (i.e., groups had approximately equal variances). However, results indicated no statistically significant differences in motivation to enact positive humor between training types when controlling for humor orientation $\left(F(1,298)=.11, p=.75, \eta_{\mathrm{p}}{ }^{2}=\right.$ .11 , observed power $=.06$, treatment group $(M=2.97, S D=.19)$, comparison group $(M=2.99$, $S D=.19)$

Results of repeated measures ANCOVA indicated that there was not a statistically significant change in motivation to enact positive humor scores for the training types from the pre-test to the post-test $\left(F(1,146)=5.22, p=.06, \eta_{\mathrm{p}}{ }^{2}=.01\right.$, observed power $=.69$; pre-test $(M=$ $2.88, S D=.21)$, post-test $(M=2.97, S D=.19)$. There was also not a statistically significant change in motivation to enact positive humor for the comparison group from the pre-test to the post-test $\left(F(1,149)=3.20, p=.02, \eta_{\mathrm{p}}^{2}=.007\right.$, observed power $=.42$; pre-test $(M=2.88, S D=$ $.19)$, post-test $(M=2.99, S D=.19)$. Therefore, there were no statistically significant differences between the training types on motivation to enact positive humor at the post-test, and individuals in the humor skills training group did not report a significant change in motivation to enact positive humor from the pre-test to the post-test.

Motivation to avoid negative humor. ANCOVA was conducted with motivation to avoid negative humor as the dependent variable, training type as the fixed factor, and humor orientation as the covariate. The Levene's test of equality of error variances was not statistically significant $(p=.97)$, assuring homogeneity (i.e., groups had approximately equal variances). However, results indicated no statistically significant differences in motivation to avoid using 
negative humor between training types when controlling for humor orientation $(F(1,298)=.39$, $p=.53, \eta_{\mathrm{p}}^{2}=.001$, observed power $=.10$, treatment group $(M=2.76, S D=.24)$, comparison group $(M=2.81, S D=.24)$.

Results of repeated measures ANCOVA indicated that there was not a statistically significant change in motivation to avoid negative humor scores for the treatment group from the pre-test to the post-test $\left(F(1,149)=.30, p=.02, \eta_{\mathrm{p}}{ }^{2}=.002\right.$, observed power $=.08$; pre-test $(M=$ $2.73, S D=.22)$, post-test $(M=2.76, S D=.24)$. There was also not a statistically significant change in motivation to avoid negative humor for the comparison group from the pre-test to the post-test $\left(F(1,146)=.14, p=.71, \eta_{\mathrm{p}}{ }^{2}=.002\right.$, observed power $=.07$, pre-test $(M=2.80, S D=$ $.24)$, post-test $(M=2.81, S D=.24)$. Therefore, there were no statistically significant differences between the training types on motivation to avoid negative humor at the post-test, and individuals in the humor skills training group did not report a significant change in motivation to avoid negative humor from the pre-test to the post-test. Hypothesis five was not supported.

Hypothesis 6. Hypothesis 6 predicted that humor communication skills training would affect humor use such that individuals in the treatment group would report (a) using more positive humor and avoiding negative humor more than those in the comparison group, and (b) an increase in humor use scores from the pre-test to the post-test.

Positive humor use. ANCOVA was conducted with positive humor use as the dependent variable, training type as the fixed factor, and humor orientation as the covariate. The Levene's test of equality of error variances was not statistically significant $(p=.23)$, assuring homogeneity (i.e., groups had approximately equal variances). However, results indicated no statistically significant differences in positive humor use between training types when controlling for humor 
orientation $\left(F(1,298)=1.67, p=.42, \eta_{\mathrm{p}}^{2}=.52\right.$, observed power $=.10$, treatment group $(M=$ 4.12, $S D=.16)$, comparison group $(M=4.17, S D=.16)$.

Although there were no statistically significant differences between the training types on positive humor use, results of repeated measures ANCOVA indicated a statistically significant increase in positive humor use for the treatment group from the pre-test to the post-test measure $\left(F(1,149)=111.16, p<.001, \eta_{\mathrm{p}}^{2}=.43\right.$, observed power $=1.00$, pre-test $(M=3.42, S D=.20)$, post-test $(M=4.12, S D=.16)$. However, there was not a statistically significant change in positive humor use for the comparison group from the pre-test to the post-test $(F(1,146)=1.82$, $p=.18, \eta_{\mathrm{p}}{ }^{2}=.02$, observed power $=.27$, pre-test $(M=4.26, S D=.13)$, post-test $(M=4.17, S D=$ .16). Therefore, there were no statistically significant differences between the training types on positive humor use at the post-test, however individuals in the humor skills training group did report a significant change in positive humor use from the pre-test to the post-test.

Avoidance of negative humor. ANCOVA was conducted with avoidance of negative humor as the dependent variable, training type as the fixed factor, and humor orientation as the covariate. The Levene's test of equality of error variances was not statistically significant $(p=$ .74), assuring homogeneity (i.e., groups had approximately equal variances). However, results indicated no statistically significant differences in avoidance of negative humor use between training types when controlling for humor orientation $\left(F(1,298)=2.01, p=.16, \eta_{\mathrm{p}}{ }^{2}=.01\right.$, observed power $=.29$, treatment group $(M=3.44, S D=.23)$, comparison group $(M=3.59, S D=$ $.23)$.

Results of repeated measures ANCOVA indicated that there was not a statistically significant change in the avoidance of negative humor scores for the treatment group from the pre-test to the post-test $\left(F(1,149)=.02, p=.000, \eta_{\mathrm{p}}{ }^{2}=.002\right.$, observed power $=.05$, pre-test $(M$ 
$=3.78, S D=.14)$, post-test $(M=3.44, S D=.23)$. There was also not a statistically significant change in avoidance of negative humor scores for the comparison group from the pre-test to the post-test $\left(F(1,146)=1.82, p=.18, \eta_{\mathrm{p}}{ }^{2}=.002\right.$, observed power $=.27$, pre-test $(M=3.51, S D=$ $.17)$, post-test $(M=3.59, S D=.23)$. Therefore, there were no statistically significant differences between the training types on the avoidance of negative humor at the post-test, and individuals in the humor skills training group did not report a significant change in negative humor use from the pre-test to the post-test. Hypothesis six was not supported. Table 10 presents means and standard deviations for all variables in the treatment and comparison group at the post-test (Time 2) controlling for humor orientation.

Table 10: Treatment and Comparison Group Post-Test Scores Controlling for HO. Mean, Standard Deviation in Parentheses.

\begin{tabular}{|llllcl|}
\hline Variable & $\begin{array}{l}\text { Treatment } \\
\text { Group }\end{array}$ & $\begin{array}{l}\text { Comparison } \\
\text { Group }\end{array}$ & $\boldsymbol{d} \boldsymbol{f}$ & $\boldsymbol{f}$-value & $\boldsymbol{p}$ \\
\hline 1. Affiliative Humor & $4.20(.25)$ & $4.15(.25)$ & 1,298 & .05 & .82 \\
\hline 2. Self-enhancing Humor & $3.64(.35)$ & $3.48(.37)$ & 1,298 & $5.72^{*}$ & .02 \\
\hline 3. Aggressive Humor & $2.85(.40)$ & $2.92(.40)$ & 1,298 & 1.26 & .26 \\
\hline 4. Self-defeating humor & $2.67(.43)$ & $2.75(.44)$ & 1,298 & 1.32 & .21 \\
\hline 5. Cognitive Learning & $.78(.20)$ & $.52(.21)$ & 1,298 & $114.86^{* *}$ & .000 \\
\hline 6. Self-efficacy Positive & $7.32(.83)$ & $6.97(.84)$ & 1,298 & $5.52^{*}$ & .02 \\
\hline 7. Self-efficacy Negative & $6.85(1.12)$ & $6.50(1.26)$ & 1,298 & $5.27^{*}$ & .02 \\
\hline 8. Motivation Positive & $2.97(.19)$ & $2.99(.19)$ & 1,298 & .11 & .75 \\
\hline 9. Motivation Negative & $2.76(.24)$ & $2.81(.24)$ & 1,298 & .39 & .53 \\
\hline 10. Humor Use Positive & $4.12(.16)$ & $4.17(.16)$ & 1,298 & 1.67 & .42 \\
\hline 11. Humor Use Negative & $3.44(.23)$ & $3.59(.23)$ & 1,298 & 2.01 & .16 \\
\hline
\end{tabular}

Note. $* p<.05 . * * p<.001$.

Research Question 1. Research question one asked how humor communication skills training would affect humor style, cognitive learning, self-efficacy, motivation, and humor use two weeks after the training program.

Affiliative humor. To assess pro-social humor styles, ANCOVA was first conducted with affiliative humor as the dependent variable, training type as the fixed factor, and humor 
orientation as the covariate. The Levene's test of equality of error variances was not statistically significant ( $p=.79$ ), assuring homogeneity (i.e., groups had approximately equal variances). However, results indicated no statistically significant differences in affiliative humor by training type at the two week follow-up when controlling for humor orientation $(F(1,206)=.96, p=.33$, $\eta_{\mathrm{p}}{ }^{2}=.005$, observed power $=.16$, treatment group $(M=4.00, S D=.43)$, comparison group $(M=$ $3.94, S D=.42)$.

Results of repeated measures ANCOVA indicated that there was a statistically significant decrease in affiliative humor for the humor skills training group from the post-test to the two week follow-up $\left(F(1,105)=7.96, p=.01, \eta_{\mathrm{p}}{ }^{2}=.07\right.$, observed power $=.80$, post-test $(M=4.20$, $S D=.25)$, follow-up $(M=4.00, S D=.43)$. There was also a statistically significant decrease in affiliative humor scores for the comparison group from the post-test to the two week follow-up $\left(F(1,105)=2.93, p=.01, \eta_{\mathrm{p}}{ }^{2}=.07\right.$, observed power $=.77$, post-test $(M=4.15, S D=.25)$, follow-up $(M=3.93, S D=.36)$. Therefore, there were no statistically significant differences between the training types at the two week follow-up, and the effect of the humor skills training program on affiliative humor was not maintained as scores decreased from the treatment and comparison groups from the post-test to the follow-up test.

Self-enhancing humor. ANCOVA was conducted with self-enhancing humor as the dependent variable, training type as the fixed factor, and humor orientation as the covariate. The Levene's test of equality of error variances was statistically significant $(p=.01)$, assuring nonhomogeneity (i.e., groups did not have approximately equal variances). Results indicated statistically significant differences in self-enhancing humor by training type at the two week follow-up when controlling for humor orientation $\left(F(1,204)=2.87, p=.09, \eta_{\mathrm{p}}{ }^{2}=.014\right.$, power 
$=.39$ ). Specifically, participants in the humor skills training group reported using more selfenhancing humor $(M=3.54, S D=.37)$ than those in the comparison group $(M=3.43, S D=.48)$. Results of repeated measures ANCOVA indicated a statistically significant decrease in self-enhancing humor scores for the treatment group from the post-test to the two week follow$\operatorname{up}\left(F(1,105)=4.75, p=.03, \eta_{\mathrm{p}}{ }^{2}=.04\right.$, observed power $=.57$, post-test $(M=3.64, S D=.35)$, follow-up $(M=3.54, S D=.37)$. However, there was not a statistically significant change in selfenhancing humor scores for the comparison group from the post-test to the two-week follow-up $\left(F(1,105)=.06, p=.80, \eta_{\mathrm{p}}^{2}=.001\right.$, observed power $=.06$, post-test $(M=3.48, S D=.37)$, follow-up $(M=3.43, S D=.48)$. Therefore, although there were statistically significant differences between the training types at the two week follow-up, with the treatment group reporting more self-enhancing humor, the effect of the humor skills training program on selfenhancing humor was not maintained as scores decreased for the treatment group from the posttest to the follow-up test.

Aggressive humor. To assess anti-social humor styles, ANCOVA was first conducted with aggressive humor as the dependent variable, training type as the fixed factor, and humor orientation as the covariate. The Levene's test of equality of error variances was not statistically significant $(p=.39)$, assuring homogeneity (i.e., groups had approximately equal variances). However, results indicated no statistically significant differences in aggressive humor between training types at the two week follow-up when controlling for humor orientation $(F(1,205)=$ $1.63, p=.20, \eta_{\mathrm{p}}{ }^{2}=.008$, power $=.25$, treatment group $(M=2.96, S D=.42)$, comparison group $(M=2.86, S D=.46)$.

Results of repeated measures ANCOVA indicated that there was not a statistically significant change in aggressive humor scores for the treatment group from the post-test to the 
two week follow-up measure $\left(F(1,105)=.49, p=.49, \eta_{\mathrm{p}}{ }^{2}=.005\right.$, observed power $=.12$, posttest $(M=2.85, S D=.40)$, follow-up $(M=2.96, S D=.42)$. There was also not a statistically significant change in aggressive humor scores for the comparison group from the post-test to the two week follow-up $\left(F(1,105)=.93, p=.34, \eta_{\mathrm{p}}{ }^{2}=.01\right.$, observed power $=.15$, post-test $(M=$ 2.92, $S D=.40)$, follow-up $(M=2.86, S D=.46)$. Therefore, the effect of the humor skills training program on aggressive humor was not maintained as there was not a statistical difference in scores from the post-test to the follow-up test.

Self-defeating humor. ANCOVA was conducted with self-defeating humor as the dependent variable, training type as the fixed factor, and humor orientation as the covariate. The Levene's test of equality of error variances was not statistically significant $(p=.17)$, assuring homogeneity (i.e., groups had approximately equal variances). However, results indicated no statistically significant differences in self-defeating humor between training types at the twoweek follow-up when controlling for humor orientation $\left(F(1,207)=.71, p=.40, \eta_{\mathrm{p}}{ }^{2}=.003\right.$, observed power $=.13)$, treatment group $(M=2.66, S D=.46)$, comparison group $(M=2.74, S D=$ $.55)$.

Results of repeated measures ANCOVA indicated that there was not a statistically significant change in self-defeating humor scores for the treatment group from the post-test to the two week follow-up $\left(F(1,105)=2.13, p=.15, \eta_{\mathrm{p}}{ }^{2}=.02\right.$, observed power $=.30$; post-test $(M=$ 2.67, $S D=.43)$, follow-up $(M=2.66, S D=.46)$. There was also not a statistically significant change in self-defeating humor for the comparison group from the post-test to the two week follow-up $\left(F(1,105)=1.36, p=.25, \eta_{\mathrm{p}}{ }^{2}=.01\right.$, observed power $=.21$, post-test $(M=2.75, S D=$ $.44)$, follow-up $(M=2.74, S D=.55)$. Therefore, the effect of the humor communication skills 
training program on self-defeating humor was not maintained as there was not a statistically significant difference in scores from the post-test to the follow-up test.

Cognitive learning. ANCOVA was conducted with cognitive learning as the dependent variable, training type as the fixed factor, and humor orientation as the covariate. The Levene's test of equality of error variances was not statistically significant ( $p=.71)$, assuring homogeneity (i.e., groups had approximately equal variances). Results indicated statistically significant differences in cognitive learning between training types at the two week follow-up when controlling for humor orientation $\left(F(1,206)=78.78, p<.001, \eta_{\mathrm{p}}{ }^{2}=.28\right.$, observed power $=$ 1.00). Specifically, participants in the treatment group reported greater levels of cognitive learning $(M=.71, S D=.30)$ than those in the comparison group $(M=.56, S D=.31)$.

Results of repeated measures ANCOVA also indicated a statistically significant decrease in cognitive learning scores for the treatment group from the post-test to the two week follow-up $\left(F(1,105)=5.88, p=.02, \eta_{\mathrm{p}}^{2}=.05\right.$, observed power $=.67$, post-test $(M=.78, S D=.20)$, follow-up $(M=.71, S D=.29)$. However, there was not a statistically significant change in cognitive learning scores for the comparison group from the post-test to the two week follow-up $\left(F(1,105)=11.87, p=.08, \eta_{\mathrm{p}}^{2}=.03\right.$, observed power $=.93$; post-test $(M=.52, S D=.21)$, follow-up $(M=.56, S D=.31)$. Therefore, although there were statistically significant differences between training types at the two week follow-up, with the treatment group reporting greater levels of cognitive learning, the effect of the humor skills training program on cognitive learning was not maintained as scores decreased for the treatment group from the post-test to the follow-up test.

Self-efficacy to enact positive humor. ANCOVA was conducted with self-efficacy to enact positive humor as the dependent variable, training type as the fixed factor, and humor 
orientation as the covariate. The Levene's test of equality of error variances was not statistically significant ( $p=.39$ ), assuring homogeneity (i.e., groups had approximately equal variances). Results indicated statistically significant differences in self-efficacy to enact positive humor between the training types at the two week follow-up when controlling for humor orientation ( $F$ $(1,298)=5.52, p=.02, \eta_{\mathrm{p}}^{2}=.016$, observed power $\left.=.67\right)$. Specifically, participants in the treatment group reported greater self-efficacy to enact positive humor $(M=6.88, S E=1.29)$ than those in the comparison group $(M=6.34, S E=1.25)$.

Results of repeated measures ANCOVA also indicated a statistically significant decrease in self-efficacy to enact positive humor scores for the treatment group from the post-test to the two week follow-up $\left(F(1,105)=4.47, p=.03, \eta_{\mathrm{p}}{ }^{2}=.04\right.$, observed power $=.55$, post-test $(M=$ 7.32, $S D=.83)$, follow-up $(M=6.88, S D=1.29)$. There was also a statistically significant decrease in self-efficacy to enact positive humor for the comparison group from the post-test to the two week follow-up $\left(F(1,105)=16.33, p<.001, \eta_{\mathrm{p}}{ }^{2}=.14\right.$, observed power $=.98$, post-test $(M=6.97, S D=.84)$, follow-up $(M=6.34, S D=1.25)$. Therefore, although there were statistically significant differences between the training types at the two week follow-up, with the treatment group reporting greater self-efficacy to enact positive humor, the effect of the humor skills training program on self-efficacy to enact positive humor was not maintained as scores decreased for the treatment group from the post-test to the follow-up test.

Self-efficacy to avoid negative humor. ANCOVA was conducted with self-efficacy to avoid enacting negative humor as the dependent variable, training type as the fixed factor, and humor orientation as the covariate. The Levene's test of equality of error variances was not statistically significant $(p=.58)$, assuring homogeneity (i.e., groups had approximately equal variances). Results indicated statistically significant differences in self-efficacy to avoid 
enacting negative humor between the training types at the two-week follow-up when controlling for humor orientation $\left(F(1,208)=5.23, p=.02, \eta_{\mathrm{p}}{ }^{2}=.03\right.$, observed power $\left.=.63\right)$. Specifically, participants in the humor skills training group reported more self-efficacy to avoid negative humor $(M=6.60, S D=1.54)$ than those in the comparison group $(M=5.76, S D=1.47)$.

Results of repeated measures ANCOVA also indicated a statistically significant decrease in self-efficacy to avoid negative humor scores for the treatment group from the post-test to the two-week follow-up $\left(F(1,103)=2.77, p=.05, \eta_{\mathrm{p}}{ }^{2}=.03\right.$, observed power $=.58$, post-test $(M=$ $6.85, S D=1.12)$, follow-up $(M=6.60, S D=1.24)$. There was also a statistically significant decrease in self-efficacy to avoid negative humor for the comparison group from the post-test to the two week follow-up $\left(F(1,105)=11.33, p=.001, \eta_{\mathrm{p}}{ }^{2}=.03\right.$, observed power $=.92$, post-test $(M=6.50, S D=1.26)$, follow-up $(M=5.76, S D=1.47)$. Therefore, although there were statistically significant differences between the treatment types at the two week follow-up, with the treatment group reporting greater self-efficacy to avoid negative humor, the effect of the humor skills training program on self-efficacy to avoid negative humor was not maintained as scores decreased for the treatment and comparison groups from the post-test to the follow-up test.

Motivation to enact positive humor. ANCOVA was conducted with humor orientation as the covariate, training type as the fixed factor, and motivation to enact positive humor as the dependent variable. The Levene's test of equality of error variances was not statistically significant ( $p=.49$ ), assuring homogeneity (i.e., groups had approximately equal variances). Results indicated no statistically significant differences in motivation to enact positive humor by training type at the two week follow-up when controlling for humor orientation $(F(1,207)=$ 
$1.21, p=.27, \eta_{\mathrm{p}}{ }^{2}=.01$, observed power $=.20$; treatment group $(M=2.82, S D=.20)$, comparison group $(M=2.91, S D=.23)$.

Results of repeated measures ANCOVA indicated that there was not a statistically significant change in motivation to enact positive humor scores for the treatment group from the post-test to the two week follow-up $\left(F(1,105)=2.46, p=.12, \eta_{\mathrm{p}}{ }^{2}=.02\right.$, observed power $=.34$; post-test $(M=2.97, S D=.19)$, follow-up $(M=2.82, S D=.20)$. There was also not a statistically significant change in motivation to enact positive humor for the comparison group from the posttest to the two week follow-up $\left(F(1,105)=4.19, p=.05, \eta_{\mathrm{p}}{ }^{2}=.007\right.$, observed power $=.53$, post-test $(M=2.99, S D=.19)$, follow-up $(M=2.91, S D=.23)$. Thus, there were no statistically significant differences between training types at the two week follow-up, and the effect of the humor skills training program on motivation to enact positive humor was not maintained as there was not a statistical difference in scores from the post-test to the follow-up test.

Motivation to avoid negative humor. ANCOVA was conducted with motivation to avoid negative humor as the dependent variable, training type as the fixed factor, and humor orientation as the covariate. The Levene's test of equality of error variances was not statistically significant $(p=.53)$, assuring homogeneity (i.e., groups had approximately equal variances). However, results indicated no statistically significant differences in motivation to avoid using negative humor between training types at the two week follow-up when controlling for humor orientation $\left(F(1,208)=.87, p=.35, \eta_{\mathrm{p}}^{2}=.01\right.$, observed power $=.15$, treatment group $(M=$ 2.68, $S D=.25)$, comparison group $(M=2.77, S D=.26)$.

Results of repeated measures ANCOVA indicated that there was not a statistically significant change in motivation to avoid negative humor scores for the treatment group from the post-test to the two-week follow-up $\left(F(1,105)=.10, p=.76, \eta_{\mathrm{p}}{ }^{2}=.002\right.$, observed power $=.06$, 
post-test $(M=2.76, S D=.24)$, follow-up $(M=2.68, S D=.25)$. There was also not a statistically significant change in motivation to avoid negative humor for the comparison group from the post-test to the two week follow-up $\left(F(1,105)=.26, p=.61, \eta_{\mathrm{p}}{ }^{2}=.002\right.$, observed power $=.08$, post-test $(M=2.82, S D=.24)$, follow-up $(M=2.77, S D=.26)$. Thus, there were no statistically significant differences between training types at the two week follow-up, and the effect of the humor skills training program on motivation to avoid negative humor was not maintained as there was not a statistical difference in scores from the post-test to the follow-up test.

Positive humor use. ANCOVA was conducted with positive humor use as the dependent variable, training type as the fixed factor, and humor orientation as the covariate. The Levene's test of equality of error variances was not statistically significant $(p=.85)$, assuring homogeneity (i.e., groups had approximately equal variances). However, results indicated no statistically significant differences in positive humor use between training types at the two week follow-up when controlling for humor orientation $\left(F(1,208)=.53, p=.99, \eta_{\mathrm{p}}{ }^{2}=.003\right.$, observed power $=$ .05 , treatment group $(M=3.96, S D=.24)$, comparison group $(M=3.98, S D=.22)$.

Results of repeated measures ANCOVA indicated that there was not a statistically significant change in positive humor use scores for the treatment group from the post-test to the two-week follow-up $\left(F(1,105)=.71, p=.40, \eta_{\mathrm{p}}{ }^{2}=.007\right.$, observed power $=.13$, post-test $(M=$ $4.12, S D=.16)$, follow-up $(M=3.96, S D=.24)$. There was also not a statistically significant change in positive humor use for the comparison group from the post-test to the two week follow-up $\left(F(1,105)=4.54, p=.06, \eta_{\mathrm{p}}{ }^{2}=.002\right.$, observed power $=.55$; post-test $(M=4.17, S D$ $=.16)$, follow-up $(M=3.98, S D=.22)$. Thus, there were no statistically significant differences between training types at the two week follow-up, and the effect of the humor skills training 
program on positive humor use was not maintained as there was not a statistically significant difference in scores from the post-test to the follow-up test.

Avoidance of negative humor. ANCOVA was conducted with avoidance of negative humor as the dependent variable, training type as the fixed factor, and humor orientation as the covariate. The Levene's test of equality of error variances was not statistically significant $(p=$ .74), assuring homogeneity (i.e., groups had approximately equal variances). However, results indicated no statistically significant differences in avoidance of negative humor between training types at the two week follow-up when controlling for humor orientation $(F(1,208)=2.01, p=$ $.16, \eta_{\mathrm{p}}{ }^{2}=.01$, observed power $=.29$; treatment group $(M=3.35, S D=.28)$, comparison group $(M=3.50, S D=.26)$.

Results of repeated measures ANCOVA indicated that there was not a statistically significant change in the avoidance of negative humor scores for the treatment group from the post-test to the two week follow-up $\left(F(1,105)=.005, p=.94, \eta_{\mathrm{p}}{ }^{2}=.002\right.$, observed power $=.05$, post-test $(M=3.44, S D=.23)$, follow-up $(M=3.35, S D=.28)$. There was also not a statistically significant change in avoidance of negative humor scores for the comparison group from the post-test to the two week follow-up $\left(F(1,105)=.52, p=.47, \eta_{\mathrm{p}}{ }^{2}=.005\right.$, observed power $=.11$, post-test $(M=3.59, S D=.23)$, follow-up $(M=3.47, S D=.26)$. Thus, there were no statistically significant differences between training types at the two week follow-up, and the effect of the humor skills training program on the avoidance of negative humor use was not maintained as there was not a difference in scores from the post-test to the follow-up test. Table 11 presents treatment and comparison group variable means and standard deviations at baseline, post-test, and the two week follow-up controlling for humor orientation. 
Table 11: Treatment and Comparison Group Baseline, Post-test, and Two Week Follow-up Scores Controlling for HO. Mean, Standard Deviation in Parentheses

\begin{tabular}{|llll|}
\hline Variable & Time & $\begin{array}{l}\text { Treatment } \\
\text { Group }\end{array}$ & $\begin{array}{l}\text { Comparison } \\
\text { Group }\end{array}$ \\
\hline 1. Affiliative Humor & Pre-test & $3.47(.38)$ & $4.07(.24)$ \\
& Post-test & $4.20(.25)$ & $4.15(.25)$ \\
& Follow-up & $4.00(.43)$ & $3.93(.36)$ \\
\hline 2. Self-enhancing Humor & Pre-test & $3.55(.37)$ & $5.52(42)$ \\
& Post-test & $3.64(.35)$ & $3.48(.37)$ \\
& Follow-up & $3.54(.37)$ & $3.43(.48)$ \\
\hline 3. Aggressive Humor & Pre-test & $2.90(.39)$ & $2.80(.37)$ \\
& Post-test & $2.85(.40)$ & $2.92(.40)$ \\
& Follow-up & $2.96(.42)$ & $2.86(.46)$ \\
\hline 4. Self-defeating humor & Pre-test & $2.62(.44)$ & $2.67(.45)$ \\
& Post-test & $2.67(.43)$ & $2.75(.44)$ \\
& Follow-up & $2.66(.46)$ & $2.74(.55)$ \\
\hline 5. Cognitive Learning & Pre-test & $.54(.21)$ & $.55(.18)$ \\
& Post-test & $.78(.20)$ & $.52(.21)$ \\
& Follow-up & $.71(.29)$ & $.56(.31)$ \\
\hline 6. Self-efficacy Positive & Pre-test & $6.83(.84)$ & $6.98(.78)$ \\
& Post-test & $7.32(.83)$ & $6.97(.84)$ \\
& Follow-up & $6.88(1.29)$ & $6.34(1.25)$ \\
\hline 7. Self-efficacy Negative & Pre-test & $6.52(1.16)$ & $6.44(1.27)$ \\
& Post-test & $6.85(1.12)$ & $6.50(1.26)$ \\
& Follow-up & $6.60(1.54)$ & $5.76(1.47)$ \\
\hline 8. Motivation Positive & Pre-test & $2.88(.21)$ & $2.88(.19)$ \\
& Post-test & $2.97(.19)$ & $2.99(.19)$ \\
& Follow-up & $2.82(.20)$ & $2.91(.23)$ \\
\hline 9. Motivation Negative & Pre-test & $2.73(.22)$ & $2.80(.24)$ \\
& Post-test & $2.76(.24)$ & $1.41(.24)$ \\
& Follow-up & $2.68(.25)$ & $2.77(.26)$ \\
\hline 10. Humor Use Positive & Pre-test & $3.42(.20)$ & $4.26(.13)$ \\
& Post-test & $4.12(.16)$ & $4.17(.16)$ \\
& Follow-up & $3.96(.24)$ & $3.98(.22)$ \\
\hline 11. Humor Use Negative & Pre-test & $3.78(.14)$ & $3.51(.17)$ \\
& Post-test & $3.44(.23)$ & $3.59(.23)$ \\
& Follow-up & $3.35(.28)$ & $3.47(.26)$ \\
\hline
\end{tabular}

Note. $* p<.05 . * * p<.001$. 


\section{Summary}

This chapter reported the findings of this dissertation. Results of hypotheses 1-6 showed that individuals in the treatment group (i.e., humor communication skills training), reported employing greater self-enhancing humor, self-efficacy to enact positive and avoid negative humor, and cognitive learning, than those in the comparison group. However, there were no statistically significant differences between treatment and comparison group scores on affiliative humor, aggressive humor, self-defeating humor, motivation to communicate positive and to avoid negative humor, or self-reported positive humor use. The final chapter discusses the research findings in detail and offers several explanations for the results, practical implications, limitations, and directions for future research. 


\section{Chapter Four}

\section{Discussion}

Social Cognitive Theory suggests that cognition, self-efficacy, and motivation play a major role in the acquisition and maintenance of behaviors, while providing a basis for skills training (Bandura, 1997). The current study was undertaken to learn more about the effects of humor communication skills training in the interpersonal communication context. Based on the perspective of SCT, it was expected that individuals who participated in humor skills training would enhance their pro-social humor styles (i.e. affiliative and self-enhancing), and minimize their anti-social humor styles (i.e., aggressive and self-defeating) in interpersonal interactions. It was also expected that individuals would improve in cognitive learning, self-efficacy, motivation, and positive humor use upon completion of the training program.

As predicted, participants in the humor skills training program reported improving in self-enhancing humor, cognitive learning, and self-efficacy upon completion of the final training session. However, they did not improve in affiliative humor, anti-social humor styles, motivation, or positive humor use. Furthermore, individuals in the humor skills training group maintained higher levels of self-enhancing humor, cognitive learning, and self-efficacy two weeks after the final training session. This provides some support for SCT and suggests that humor skills training may help people to enhance their pro-social humor style, self-efficacy, and knowledge regarding general humor use.

The next sections of this chapter describe the results concerning the hypotheses and research question for this dissertation. Findings related to humor styles will be explained first, followed by a detailed discussion on cognitive learning, self-efficacy, motivation, and selfreported humor use. Finally, limitations and implications for future research will be addressed. 


\section{Humor Styles}

Pro-social humor. Although there were no differences between the training types on affiliative humor at the post-test, individuals in the treatment and comparison groups both improved on affiliative humor from the pre-test to the post-test. Additionally, individuals in the humor skills training group used more self-enhancing humor after the training than those in the comparison group, and improved on self-enhancing humor from the start to the conclusion of the training program.

There are several plausible reasons for these findings. First, it is necessary to examine the study design and the humor communication skills training program developed for this investigation. In regard to the increase in affiliative humor for individuals in the treatment and comparison group from the pre-test to the post-test measure, it is important to consider recruitment strategies for participants in the current study. Recall that affiliative humor is otheroriented and aimed at facilitating interpersonal relationships and reducing interpersonal conflict (Martin et al., 2003). Participants in the treatment and comparison group were recruited from interpersonal communication courses, thus it is possible that general communication skills learned in the course impacted perceptions of affiliative humor in interpersonal interactions.

Additionally, the large size of the training group may have influenced study results. Humor communication skills training was conducted during regularly scheduled class periods in groups ranging from 57 to 152 participants. During the training sessions, participants were asked to work in smaller groups of approximately $4-5$ people. Group members engaged in brainstorming exercises, role playing activities, and provided each other with feedback. Although the researcher did provide each small group with general feedback, the large size of the class made it difficult to interact with the trainees one-on-one. Research investigating the effects 
of general communication skills training indicates that smaller training groups (e.g., 20 or less people), allow the trainer to work one-on-one with individuals, and encourages participants to engage in the content in a more active manner and take a greater responsibility in the learning process (Hommes \& Van der Molen, 2012). Therefore, it is likely that training smaller groups of people may be more effective.

More training time may also be needed to influence a change in behavior. Previous research suggests that a total of approximately four hours of communication skills training is adequate to achieve a significant effect on communication behaviors such as the enactment of negative messages in interpersonal relationships (Halford et al). For example, Halford and colleagues conducted a four-hour skills training program aimed at helping marital partners enhance relational communication and conflict skills. The program involved informational sessions taught by the trainer and couple discussions of the material. Upon completion of the skills training program, marital partners reported reduced levels of overall negative communication between spouses, reduced conflict communication, and increased marital satisfaction. In the current investigation, the humor communication skills training program totaled 3.75 hours. Therefore, extending the overall training time to at least four hours or more may have a greater impact on behavioral change.

On a positive note, while levels of self-enhancing humor remained relatively stable for those in the comparison group, participants in the humor skills training group reported an increase in self-enhancing humor upon completion of the program. Recall that self-enhancing humor is a self-oriented construct and is often used as a coping mechanism for dealing with stressful situations (Martin et al., 2003). In the health context, Falkenberg and colleagues (2010) examined the ability of a manual based humor skills training program to help adult patients deal 
with depression. After being presented with information describing how to use self-enhancing humor to cope with stress, participants reported greater levels of self-enhancing humor, copying efficacy, and cheerfulness. Similarly, in the current study, upon completion of the humor skills training program, individuals also reported using humor more as a coping mechanism (i.e., selfenhancing humor) in general interpersonal interactions.

Another possible explanation for the increase in self-enhancing humor as opposed to affiliative humor is linked to the culture in which the humor skills training program was conducted. Kuiper, Kazarian, Sine, and Bassil (2010) conducted a study examining cultural distinctions in humor styles and found that those in individualistic cultures reported using greater levels of self-enhancing humor and lower levels of affiliative humor in general. More specifically, American students reported employing self-enhancing humor to benefit the self, rather than employing affiliative humor aimed at benefiting others and enhancing interpersonal relationships (Kuiper et al., 2010). Therefore, perhaps in American culture, individuals are more likely to apply humor communication skills to benefit the self, rather than to benefit others. Additionally, it is possible that people may need to practice and perfect using humor to manage their own emotions, before being able to apply humor communication skills to help others deal with stressful situations.

Results of research question one indicated that although individuals in the humor skills training group reported using more self-enhancing humor at a two week follow-up than those in the comparison group, they also reported a decrease in self-enhancing humor from the post-test to the follow-up test. One explanation for this finding is that students generally overestimate their skill before training and afterward this overestimation may disappear or lead to an underestimation of their skills (Crews et al., 2005). One way to compensate for this effect is to 
provide trainees with supportive feedback throughout the skills training program (Crews et al., 2005). Therefore, future studies should conduct humor skills training among smaller groups to allow the researcher to provide individual feedback throughout each training session. Training may also be extended beyond the classroom through web sources such as online learning communities and social networking sites to provide feedback during and after a training program.

Anti-social humor. Although unexpected, there were no differences between the training types on anti-social humor styles at the post-test. Additionally, individuals in the humor skills training group did not report a significant change in aggressive or self-defeating humor styles from the pre-test to the post-test. Results of research question one also indicated no significant changes in anti-social humor styles at a two week follow-up.

Humor styles may be difficult to change (Martin et al., 2003). Rather than focusing on how people react to different situations by using humor and laughter, humor styles focus on how individuals spontaneously produce positive or negative humor in their daily lives (Martin et al.). Therefore, positive and negative humor styles are often employed in social interactions and used as a coping communication for dealing with difficult situations (Martin et al., Wanzer \& BoothButterfild, 2012). Due to their frequent use, humor styles may be ingrained and difficult to change.

Furthermore, personality traits are among the underlying factors that influence negative communication in general (Feindler \& Engel, 2011). Humor orientation, the predisposition to use humor, is one personality trait that may particularly influence humor styles. (BoothButterfield \& Booth-Butterfield, 1991; Martin et al., 2003). Thus, the variable humor orientation was controlled for in this investigation. However, research indicates that other personality traits 
such as neuroticism and hostility may also play a role in the underlying communication of negative messages (Feindler \& Engel). Furthermore, aggressive and self-defeating humor are positively associated with neuroticism, and negatively associated with agreeableness and conscientiousness (Martin et al.). Therefore, in addition to HO, future research should also consider examining and controlling for various other personality traits that may influence the enactment of negative communication in general and subsequently negative humor.

Once again, to better understand the results of the current study, it is necessary to examine the humor communication skills training program. To train individuals how to reduce the use of anti-social humor styles in interpersonal interactions, the researcher showed video clips to depict anti-social humor styles and related consequences. A brainstorming activity was also conducted to help participants identify triggers of aggressive humor. Feedback was then provided to the entire group and potential solutions were discussed for using pro-social humor styles rather than anti-social humor styles to deal with various situations. Despite these efforts, perhaps a different or more powerful demonstration, such as role playing, is needed to impact anti-social humor styles.

For instance, Mahin and colleagues (2012) examined the effects of conflict resolution skills training. The training sessions included knowledge segments in which participants were provided with information on how to manage conflict with a spouse, and a skills component in which participants engaged in role playing exercises to practice enhancing positive communication and minimizing negative communication in conflict situations. Results indicated that marital partners reported using less negative communication upon completion of the six hour training program (Mahin et al.). Therefore, perhaps role-playing exercises, smaller training 
groups, and a longer skills training program may aid in the adjustment of anti-social humor styles.

\section{Cognitive Learning}

Social Cognitive Theory suggests the people draw on their knowledge, cognitive, and behavioral skills in interpersonal interactions (Bandura, 2001). Using knowledge as a guide, individuals monitor their communication and behaviors. When new knowledge is introduced, this often encourages people to change previous behaviors in order to ensure a more positive reward or outcome associated with an interaction or situation (Bandura). To assess how much people learned from humor skills training, a cognitive learning measure was developed for this study and was assessed at all three data collections. Individuals in the humor skills training group reported greater levels of cognitive learning on the post-test measure than those in the comparison group, and an improvement in cognitive learning after the final training session.

Applying the framework of SCT (Bandura, 1986, 2001), the humor communication skills training program incorporated a PowerPoint presentation focused on the cognition/knowledge component of training. First, distinctions were made between humor orientation and humor style. Second, definitions and examples were presented for each of the humor styles (i.e., affiliative, self-enhancing, aggressive, and self-defeating). Third, participants were informed about the benefits and consequences of positive and negative humor use in interpersonal interactions. Therefore, SCT was shown as a viable framework for understanding the role of humor skills training on knowledge, or cognitive learning, which is the foundation of selfefficacy and motivation.

Additionally, there was an improvement in cognitive learning after the humor skills training, and a decrease in cognitive learning from the post-test to the follow-up test. One 
explanation for this finding is that the humor communication skills training program was conducted in a classroom setting. Participants were provided with outlines for note taking, and the information taught thought was displayed in a PowerPoint presentation. Given that the students participated in the training during regularly scheduled class times, they may have been interested in learning about the particular concepts for examination purposes only, rather than learning about the concepts to enhance their interpersonal interactions. Additionally, in line with the current findings, Titsworth (2001) found that note taking was positively correlated with cognitive learning. Thus, note-taking may have also influenced perceptions of cognitive learning in the current investigation.

According to SCT, human survival relies heavily on our thoughts and subsequent actions (Bandura, 1986). Knowledge is gained through observational learning, personal experience, verbal instruction, and synthesis of pre-existing knowledge. However, new knowledge is rarely mastered right away and must be practiced before knowledge can become an effective skill in one's repertoire. Therefore, in addition to increasing knowledge regarding pro-social humor styles and subsequent outcomes, this investigation also focused on enhancing self-efficacy and motivation.

\section{Self-Efficacy}

According to SCT, self-efficacy involves the perceived ability to effectively enact a behavior (Bandura, 1986; 2001). In this investigation, individuals in the humor skills training group reported greater self-efficacy to enact positive humor and to avoid the enactment of negative humor than those in the comparison group. Additionally, people in the humor skills training group reported improving in self-efficacy upon completion of the training program. 
These findings are in line with research conducted by Crawford and Caltabiano (2011) who examined the effect of a humor skills training program on emotional well-being. Upon completion of a humor skills training program, participants reported greater self-efficacy to use coping humor (Crawford \& Caltabiano). Similarly, Hommes (2012) examined the effects of a general communication skills training program on self-efficacy, motivation, and transfer of skills. Hommes found that people who completed the skills training program reported significant increases in self-efficacy to use general communication skills. Collectively, results from these studies suggest that self-efficacy can be improved using humor skills training. Self-efficacy is subject to change over time, is a product of knowledge and experience, and can be controlled with certain interventions (Bandura, 2001). Because self-efficacy is associated with numerous positive behaviors (e.g., pro-social humor), any training program which improves self-efficacy is a valuable training resource.

Within the framework of SCT, the humor communication skills training program developed for this study incorporated all elements of the learning and modeling processes described by Bandura (1986; 2001). For instance, SCT suggests that to enhance learning and self-efficacy, the researcher must (a) gain the attention of the learner, (b) present the information in a clear way to help the learner build new schemas, (c) allow the learner to practice new behaviors, and (d) highlight the consequences or rewards associated with enacting the behavior (Bandura, 2001). Consistent with these steps, in the current investigation, the researcher incorporated video examples of pro-social and anti-social humor styles. For example, to depict aggressive humor, the researcher showed a video clip of a woman using sarcasm and putdowns in an interpersonal interaction. Participants were then asked to work in small groups of 4-5 to 
identify the humor style shown in the clip and provide alternative positive humorous approaches to the situation. The researcher also provided feedback to each group.

According to Bandura (1977), actual practice of an activity is the most influential source of self-efficacy. Therefore, an activity was also conducted to allow participants to practice enacting pro-social humor in stressful situations. The researcher divided the class into small groups of 4-5 and provided each group with a poster board and markers. The groups were instructed to engage in a brainstorming session and identify as many potential triggers of aggressive humor as possible (e.g., infidelity, hurtful messages). A spokesperson from each group presented the poster to the class. The researcher then provided general feedback and addressed various ways to approach the situations with pro-social humor rather than anti-social humor. Additionally, trainees were asked to practice enacting positive humor and avoiding negative humor in stressful situations such as those presented, and to share their experiences at the next training session. These training strategies appeared to be effective for enhancing selfefficacy after the final training period.

Furthermore, although individuals in the humor skills training group reported greater selfefficacy to enact positive humor and to avoid negative humor than those in the comparison group at a two week follow-up, they also reported a decrease in self-efficacy two weeks after the training ended. Once again, this finding may be explained by students' ability to overestimate their level of self-efficacy and skill before training and underestimate their self-efficacy or skill level after training (Crews et al., 2005). Trainers can compensate for this effect by providing trainees with supportive positive feedback throughout the skills training program (Crews et al.). Therefore, future research should conduct humor skills training among smaller groups to provide individual feedback throughout the training process. 
It is also important to note that despite the decrease in self-efficacy from the post-test to the follow-up test, self-efficacy to use positive humor was still higher in the treatment group at the follow-up than in the pre-test, and was also higher than the comparison group at the followup. Self-efficacy to avoid negative humor showed a similar pattern, with decreases from the post-test to the follow-up, but the follow-up scores were still marginally higher than from the pre-test. The inconsistency in self-efficacy could be attributed to a number of confounding variables.

For example, the lack of persistence in self-efficacy could be due to variations in participants' propensity to use the new humor styles. In other words, some participants might have been more motivated to change their humor style than others. Additionally, research indicates that self-efficacy is an enduring resource that may influence motivation to use a particular skill at any point in time (Fredrickson \& Branigan, 2005). The decline in self-efficacy from the post-test to the follow-up test could also result from lack of structured practice. Thus, perhaps more rigorous training should be implemented in future studies so that self-efficacy remains more stable over time. One way to do this might include a participant diary where they record how they use humor, their inclinations to apply the skills learned in training, and their reported successes or failures of a particular humor strategy. Alternatively, face-to-face training programs could be paired with online mini-training sessions, so that participants are exposed to training with greater frequency and for longer periods of time. Both of these strategies would allow researchers to measure participants' humor enactment in their natural settings, which would increase the ecological validity as well as participants' active attention toward improving their humor styles in their daily lives. 


\section{Motivation}

Results indicated that there were no differences between the training types on motivation to enact positive and avoid negative humor at the post-test. Additionally, individuals in the humor skills training group did not report a significant change in motivation from before training to after training. Consistent with these findings, results of research question one also showed no significant changes in motivation to enact positive or avoid negative humor at a two week follow-up.

Taken together, these findings suggest that although individuals in the humor skills training group reported being more efficacious in the ability to enact positive and avoid the enactment of negative humor (i.e., self-efficacy), they were not motivated to put these skills into action. According to SCT, there are several factors that influence the motivation to apply skills (Bandura 1977; 1986; 2001). Motivation can be influenced by (a) understanding the usefulness of the skills and (b) the consequences and/or rewards associated with such use, and (c) by receiving constructive feedback on effective application of the skills learned (Bandura).

In the current study, these processes were incorporated in the humor communication skills training program by means of modeling (e.g., video examples of good and bad application of skills), and role-playing exercises after which participants received constructive feedback from their peers. Specifically, the usefulness of positive humor and benefits of such use in interpersonal interactions were demonstrated via video clips and a lecture accompanied by a PowerPoint Presentation. Trainees were instructed to take notes on the information presented. A role-playing activity was also conducted in which participants worked in small groups of 4-5 people and acted out instances of negative humor they had recently witnessed. After discussing the consequences of the interaction with their group members, participants were instructed to 
reenact the situation using positive humor. Due to the large size of the training class, group members were asked to provide constructive feedback to each other following their role-playing performances. Although the exercises did not specifically encourage motivation to enact positive humor and avoid negative humor, the exercises were designed to improve self-efficacy, which in turn theoretically affects motivation.

Given the procedures used to influence motivation, it is possible that the large size of the training group negatively impacted participant motivation. For instance, during the role-playing activity, giving constructive feedback to fellow group members may have been a difficult task for trainees who were also busy learning the skills themselves. Therefore, future research should consider conducting training among smaller groups (e.g., 15-20 people) and only experienced trainers should provide constructive feedback to trainees (Hommes \& Van der Molen, 2012).

Furthermore, the humor communication skills training program was aimed at enhancing positive humor and minimizing negative humor in broad interpersonal interactions with various audiences. However, general communication skills training research tends to apply training to a particular audience. For example, Halford and colleagues (2010) developed a communication skills training program aimed at enhancing positive and minimizing negative communication among newlywed couples. The training was effective in teaching newly married partners how to communicate more positively in specific instances of relational conflict. Therefore, it may also be beneficial for future research to apply humor communication skills training to a specific context. For instance, newlywed couples may also benefit from learning how to effectively use positive humor and avoid negative humor in interactions involving relational conflict. Perhaps narrowing the focus of humor skills training to enhance communication with a particular audience (e.g., romantic partner, friend, family member) may motivate people to enact pro-social 
humor and avoid anti-social humor. Moreover, in order to understand the effects of humor communication skills training in different contexts and types of relationships, it is important to expand the training program beyond college students and the classroom setting.

\section{Humor Use}

According to Wexley and Latham (1991), the ultimate goal of communication skills training is that people actually start using the newly learned skills in daily interactions. The training literature refers to this as "transfer of training" (Wexley \& Latham). In the current study, the transfer of training was assessed through self-reported positive or negative humor use. Results of hypothesis six showed no differences between the training types on self-reported positive humor use or the avoidance of negative humor at the post-test. Additionally, individuals in the humor skills training group did not report a significant change in positive or negative humor use from before to after the training. In line with these findings, results of research question one showed no significant changes in positive or negative humor use from the post-test to the two week follow-up.

The self-report measure used in this investigation may have influenced study results. The measure was developed specifically for this study to first assess perceptions of positive and negative humor use in the four weeks prior to the training. Participants then responded to the measure assessing humor use in the weeks since the training began. Although the two subscales of the measure achieved reliability, and the self-reported data were informative, it is also important to investigate the effects of humor skills training using other methods, such as direct observation. 


\section{Limitations}

This dissertation offers valuable information concerning the effect of humor communication skills training. However, the results should be interpreted within the limitations of this study. First, the self-report methodology served as a limitation. Assessing perceptions of humor styles, self-efficacy, motivation, and recent positive/negative humor use, allows for the possibility of inaccurate judgment and/or social desirability bias (Kerlinger, 1986). For example, it is possible that increases in treatment group scores from the pre-test to the post-test were only found for pro-social humor styles and not anti-social humor styles due to social desirability bias. Additionally, research shows that people are not always aware of their behaviors, and transfer of training is often demonstrated by using new behaviors without being conscious of such use (Foxon, 1994).

A second limitation in this investigation is also one of its strengths. Although a strength of the study is the experimental design and the control gained by presenting the humor skills training in a classroom setting, the size of the training groups may have influenced the results. Due to the large size of the training groups, the participants were not able to get individual attention from the researcher. Therefore, future research should consider smaller training groups that allow the researcher to interact one-on-one with each participant (Crawford \& Caltabiano, 2011).

A third limitation in this study is the population sampled. The effects of humor communication skills training was only examined among college students. Future studies should also consider applying humor skills training to other populations outside of the college realm. As well, various relationship types should be taken into consideration. It is possible that positive and negative relationship cultures may influence the results of the training program (Halford et 
al., 2010). Specifically, individuals involved in negative relationships may tend to use more antisocial humor from the start and be more resistant to humor skills training. On the other hand, those in positive relationships may have a tendency to communicate more pro-social humor from the start which in turn may enhance the effects of self-efficacy, motivation, and the overall training program.

A fourth limitation in this study, as indicated in the results, is that the observed power for some analyses was below .80, which is considered low (Cohen \& Cohen, 1983). Low observed power indicates that more participants were needed in each condition to lower the risk of Type II errors (i.e., false negatives; Cohen \& Cohen).

\section{Implications and Future Research}

The purpose of this investigation was to test the effect of a humor communication skills training program on the ability to minimize anti-social humor (i.e., aggressive, self-defeating) and enhance pro-social humor (i.e., affiliative, self-enhancing) in interpersonal interactions. Based on SCT (Bandura, 1986, 2001), the effect of the humor skills training on cognitive learning, self-efficacy, motivation, and positive/negative humor use were also examined. Generally, results indicated that humor skills training had a positive impact on self-enhancing humor, self-efficacy to enact positive and avoid the enactment of negative humor, and cognitive learning. Although some findings were non-significant, the findings from this investigation provide a strong starting point for exploring the effect of humor communication skills training in the interpersonal communication context. Specifically, this study was the first to investigate humor skills training in interpersonal interactions.

To date, humor skills training research has primarily been conducted in the health context and focused on enhancing sense of humor to help people cope with difficult situations and 
medical illnesses (e.g., Falkenberg et al., 2010). Du Pre (1998) also studied humor skills training in the health care setting and argued that the choice to use humor is personal and situational, and people do not need to be "born funny" to effectively communication and understand humor. In the interpersonal communication context, the majority of skills training research aims to enhance conflict resolution skills among romantic relationship partners (e.g., Halford et al., 2010; Mahin et al., 2012). In the instructional setting, scholars have advocated for the development of humor skills training programs focused on enhancing instructor humor in the classroom (e.g., BoothButterfield, Booth-Butterfield \& Wanzer, 2007; Wanzer \& Frymier, 1999). Research also demonstrates a need for humor skills training to enhance interactions between managers and employees in the organization (Romero \& Cruthirds, 2006). The question is, can it be done successfully? The findings from the current study suggest that humor skills training can indeed improve pro-social humor, self-efficacy, and learning, in the interpersonal communication context.

Moreover, although humor communication skills training did not demonstrate a statistically significant impact on anti-social humor style, motivation, or self-reported humor use, it is still possible that the training had an impact on participants and their behaviors. According to Frey et al. (2000) "the sleeper effect occurs when an effect that is not immediately apparent becomes evident over time" (p. 120). Therefore, participants who did not report using more prosocial and less anti-social humor, or having the motivation to do so at the time of the post-test or the two week follow-up, may make a different decision at a later date or depending on a given situation. The study design sets the groundwork for other studies to examine the sleeper effect, or the impact of humor skills training over an extended period of time. 
This investigation also has implications for examining the impact of humor communication skills training in other settings including the family communication context. For example, consistent with SCT (Bandura 1986; 2001), research indicates that children learn to model their parents' behavior and communication strategies, particularly in regard to the use of positive and negative humor (Socha \& Yingling, 2010). Additionally, in a study investigating young adult perceptions of maternal and paternal warmth (i.e., acceptance) and rejection (i.e., hostility, neglect), as predictors of humor styles and happiness, the research determined that parental warmth was associated with young adult children's use of pro-social humor styles (i.e., affiliative and self-enhancing humor) and increased happiness, while parental rejection was associated with children's use of anti-social humor styles (i.e., aggressive and self-defeating humor) and decreased happiness (Kazarian, Moghnie, \& Martin, 2010). These findings indicate that parents' behavior has the potential to influence children's use of positive of negative humor styles in general (Kazarian et al., 2010). Thus, the effects of humor communication skills training on parent-child communication should also be examined by future research.

\section{Conclusion}

Humor is an important aspect of interpersonal communication and researchers should continue to explore effective training strategies to help individuals enhance positive humor styles and minimize negative humor styles in interpersonal interactions. Overall, the humor communication skills training program created for this dissertation was rooted in Bandura's Social Cognitive Theory $(1986 ; 2001)$ and empirical evidence, and may lay the foundation for future research seeking to provide others with a practical guide for enhancing interpersonal interactions through the effective use of humor. 


\section{References}

Alberts, J. K. (1990). The use of humor in managing couples' conflict interactions. In D. D. Cahn (Ed.), Intimates in conflict: A communication perspective (pp. 105-120). Hillsdale, NJ: Erlbaum.

Askari, M., Noah, S. B., Hassan, S. A., \& Baba, M. B. (2012). Comparison of the effects of communication and conflict resolution skills training on martial satisfaction. International Journal of Psychological Studies, 4, 182-195.

Bandura, A. (1977). Self-efficacy: Toward a unifying theory of behavioral change. Psychological Review, 84, 191-215.

Bandura, A. (1986). Social foundations of thought and action: A social cognitive theory. Englewood Cliffs, NJ: Prentice-Hall.

Bandura, A. (2001). Social cognitive theory: An agentic perspective. Annual Review of Psychology, 52, 1-26.

Bandura, A. (2006). Guide for constructing self-efficacy scales. In F. Pajares \& T. Urdan (Eds.), Self-efficacy beliefs of adolescents (pp. 307-337). Charlotte, NC: Information Age.

Barelds, D. P. H., \& Barelds-Dijkstra, P. (2010). Humor in intimate relationships: Ties among sense of humor, similarity in humor, and relationship quality. Humor, 23, 447465. doi:10.1515/HUMR.2010.021

Bethea, L. S. (2001). The function of humor within the lives of older adults. Qualitative Research Reports in Communication, 2, 49-56.

Bippus, A. M. (2000). Humor usage in comforting episodes: Factors predicting outcomes. Western Journal of Communication, 64, 359-384. doi:10.1080/10570310009374682 
Bippus, A. M. (2003). Humor motives, qualities, and reactions in recalled conflict episodes. Western Journal of Communication, 67, 413-426. doi:10.1080/10570310309374781

Bippus, A. M., Young, S. L., \& Dunbar, N. E. (2011). Humor in conflict discussions: Comparing partners’ perceptions. Humor, 24, 287-303. doi:10.1515/humr.2011.018

Booth-Butterfield, M. (2011). Communication in contemporary society. Action MA: Tapestry Press.

Booth-Butterfield, S. \& Booth-Butterfield, M. (1991). The communication of humor in everyday life. Southern Communication Journal, 56, 205-218.

Booth-Butterfield, M., Booth-Butterfield, S., \& Wanzer, M. (2007). Funny students cope better: Patterns of humor enactment and coping effectiveness. Communication Quarterly, 55, 299-315.

Burke, M. J. \& Day, R. R. (1986). A cumulative study of the effectiveness of managerial training. Journal of Applied Psychology, 71, 232-246.

Campbell, L., Martin, R. A., \& Ward, J. R. (2008). An observational study of humor use while resolving conflict in dating couples. Personal Relationships, 15, 41-55. doi:10.1111/j.1475-6811.2007.00183.x

Cann, A., \& Etzel, K. C. (2008). Remembering and anticipating stressors: Positive personality mediates the relationship with sense of humor. Humor, 21, 157-178.

Cann, A., Zapata, C. L., \& Davis, H. B. (2009). Positive and negative styles of humor in communication: Evidence of the importance of considering both styles. Communication Quarterly, 57, 452-468. doi:10.1515/HUMR.2011.001 
Cann, A., Zapata, C. L., \& Davis, H. B. (2011). Humor style and relationship satisfaction in dating couples: Perceived versus self-reported humor styles as predictors of satisfaction. Humor: International Journal of Humor Research, 24, 1-20. doi:10.1515/HUMOR.2011.001

Caughlin, J. P. (2003). Family communication standards: What counts as excellent family communication and how are such standards associated with family satisfaction? Human Communication Research, 29, 5-40.

Christensen, A., \& Shenk, J. L. (1991). Communication, conflict, and psychological distance in nondistressed, clinic, and divorcing couples. Journal of Consulting and Clinical Psychology, 59, 458-463.

Cohen, J. \& Cohen, P. (1983). The changing face of dating anxiety: Issues in assessment with special populations. Clinical Psychology: Science \& Practice, 15, 224-238. doi.10.1111/j.1468-2850.2008.00132.x

Comrey, A. L., \& Lee. H. B. (1994). Self-disclosure and liking: A meta-analytic review. Psychological Bulletin, 116, 457-475.

Crawford, S. A., \& Caltabiano, N. J. (2011). Promoting emotional well-being through the use of humor. The Journal of Positive Psychology, 6, 237-252. doi:10.1080/17439760.2011.577087

Crews, J., Smith, M., Smaby, M., Maddux, C., Torres-Rivera, E., Urbani, S., et al. (2005). Selfmonitoring and counseling skills: Skills-based versus interpersonal process recall training. Journal of Counseling \& Development, 83, 78-85. 
De Koning, E., \& Weiss, R. L. (2002). The relational humor inventory: Functions of humor in close relationships. The American Journal of Family Therapy, 30, 1-18. doi:10.1080/019261802753455615

Dereli, E. (2009). Examining the performance of the effect of a social skills training program for the acquisition of social problem-solving skills. An International Journal, 37, 1419-1427.

Dimitrov, D. M. \& Rumrill, P. (2003). Pretest-posttest designs in research. A Journal of Prevention, Assessment, \& Rehabilitation, 20, 159-165.

Du Pre, A. (1998). Humor and the healing arts: A multi-method analysis of humor use in health care. Mahway, NJ: Lawrence Erlbaum Associates.

Duran, R. L. (1992). Communicative adaptability: A review of conceptualization and measurement. Communication Quarterly, 40, 253-268.

Duran, R. L., \& Spitzberg, B. H. (1995). Toward the development and validation of a measure of cognitive communication competence. Communication Quarterly, 43, 259-286.

Falkenberg, I., Buchkremer, G., Bartels, M., \& Wild, B. (2010). Implementation of a manual-based training of humor abilities in patients with depression: A pilot study. Psychiatry Research, 186, 454-457. doi:10.1016/j.psychres.2010.10.009

Feindler, E. L. \& Engel, E. C. (2011). Assessment and intervention for adolescents with anger and aggression difficulties in school settings. Psychology in Schools, 48, 243-253. doi:10.1002/pits.20550

Fredrickson, B. L., \& Branigan, C. (2005). Positive emotions broaden the scope of attention and thought-action repertoires. Cognition and Emotion, 19, 313-332.

Freud, S. (1928). Humour. International Journal of Psychoanalysis, 9, 1-6. 
Frewen, P. A., Brinker, J., Martin, R. A., \& Dozois, D. A. (2008). Humor styles and personalityvulnerability to depression. Humor: International Journal of Humor Research, 21, 175195. doi: 10.1515/HUMOR.2008.009

Frey, L.R., Botan, C. H., \& Kreps, G. L. (2000). Investigating communication: An introduction to research methods. Boston, MA: Allyn \& Bacon.

Glick, B. (2003). Aggression replacement training in children and adolescents. The Hatherleigh Guide to Child and Adolescent Therapy, 5, 191-226.

Graham, E., Papa, M., \& Brooks, G. (1992). Functions of humor in conversations: Conceptualization and measurement. Western Journal of Communication, 56, 161183.

Halford, W. K., Wilson, K., Watson, B., Verner, T., Larson, J., Busby, D., \& Holman, T. (2010). Couple relationship education at home: Does skill training enhance relationship assessment and feedback? Journal of Family Psychology 24, 18-196. doi:10.1037/a0018786

Halford, W. K. (2011). Marriage and relationship education. New York, NY: Guilford Press.

Hampes, W. P. (2006). Humor and shyness: The relation between humor styles and shyness. Humor: International Journal of Humor Research, 19, 179-187. doi:10.1515/HUMOR.2006.009

Harper, M. S. \& Welsh, D. P. (2007). Keeping quiet: Self-silencing and its association with relational and individual functioning among adolescent romantic couples. Journal of Social and Personal Relationships, 24, 99-116. 
Hommes, M. A., \& Van der Molen, H. T. (2012). Effects of a self-instruction communication skills training on skills, self-efficacy, motivation, and transfer. European Journal of Open, Distance, and E-Learning, 33, 1-11.

Janes, L.M., \& Olson, J. M. (2000). Jeer pressure: The behavioral effects of observing ridicule of others. Personality and Social Psychology Bulletin, 26, 474-485.

Kazarian, S. S., Moghnie, L. \& Martin, R. A. (2010). Perceived parental warmth and rejection in childhood as predictors of humor styles and subjective happiness. Europe's Journal of Psychology, 3, 91-93.

Kehoe, J. (1995). Basic item analysis for multiple-choice tests. Practical Assessment, Research \& Evaluation, 4. Retrieved from http://pareonline.net/getvn.asp?v=4\&n=10.

Kerlinger, F. N. (1992). Foundations of behavioral research. Fort Worth, TX: Harcourt Brace College.

Kuiper, N. A., Grimshaw, M., Leite, C., \& Kirsh, G. (2004). Humor is not always the best medicine: Specific components of sense of humor and psychological well-being. Humor, 17, 135-168. doi:10.1515/humr.2004.002

Kuiper, N. A., \& Hale, N. (2009). Humor styles as mediators between self-evaluative standards and psychological well-being. The Journal of Psychology, 143, 359-376. doi:10.3200/JRLP.143.4.359-376

Kuiper, N. A., Kazarian, S. S., Sine, J., \& Bassil, M. (2010). The impact of humor in north American versus middle east cultures. Europe's Journal of Psychology, 6, 149-173. doi:10.5964/ejop.v6i3.212

Kuiper, N. A., Martin, R. A., \& Olinger, L. (1993). Coping humour, stress, and cognitive appraisals. Canadian Journal of Behavioural Science, 25, 81-96. doi:10.1037/h0078791. 
Lauer, R. H., Lauer, J. C., \& Kerr, S. T. (1990). The long-term marriage: Perceptions of stability and satisfaction. International Journal of Aging \& Human Development, 31, 189-195.

Mahin, A., Noah, S. B., Hassan, S. A., \& Baba, M. B. (2012). Comparison of the effects of communication and conflict resolution skills training on marital satisfaction. International Journal of Psychological Studies, 4, 182-195. doi:10.5539/ijps.v4n1p182

Martin, R. A. (2007). The psychology of humor: An integrative approach. London, England: Elsevier Academic Press.

Martin, R. A., Puhlik-Doris, P., Larsen, G., Gray, J., \& Weir, K. (2003). Individual differences in uses of humor and their relation to psychological well-being: Development of the humor styles questionnaire. Journal of Research in Personality, 37, 48-75.

Matthews, L. S., Wickrama, K. A., \& Conger, R. D. (1996). Predicting marital instability from spouse and observer reports of marital interaction. Journal of Marriage and the Family, $58,641-655$.

McCosker, B. \& Moran, C. C. (2012). Differential effects of self-esteem and interpersonal competence on humor styles. Journal of Psychology Research and Behavior Management, 26, 143-150.

McGhee, P. E. (1996). How to develop your sense of humor: An 8-step humor development training program. Kendall/Hunt Publishing.

McGhee, P. E. (1999). Health, healing and the amuse system: Humor as survival training ( ${ }^{\text {rd }}$ ed.). Kendal/Hunt Publishing.

Merolla, A. (2006). Decoding ability and humor production. Communication Quarterly, 54, 175-189. doi:10.1080/01463370600650886 
Meyer, J. C. (2000). Humor as a double-edged sword: Four functions of humor in communication. Communication Theory, 10, 310-331.

Rancer, A. S. \& Graham, E. E. (2012). Theories in humor. In R. L. Dicioccio (Ed.), Humor communication: Theory, impact and outcomes (pp. 3-20). Dubuque, IA: Kendall/Hunt.

Rice, S. (2000). Non-violent conflict management: Conflict resolution, dealing with anger, and negotiation and mediation. San Diego, CA: University Associates.

Romero, E., \& Cruthirds, K. W. (2006). The use of humor in the workplace. Academy of Management Perspectives, 20, 58-69.

Saroglou, V., Lacour, C., \& Demeure, M. (2010). Bad humor, bad marriage: Humor styles in divorced and married couples. Europe's Journal of Psychology, 3, 94-121.

Selda, F., \& Ferda, A. (2011). The effect of anger management training on anger coping and communication skills of adolescents. International Journal of Educational Sciences, 3, 343-369.

Spitzberg, B. H. (1983). Communication competence as knowledge, skill, and impression. Communication Education, 32, 323-329. doi:10.1080/03634528309378550

Stieger, S., Formann, A. K., \& Burger, C. (2011). Humor styles and their relationship to explicit and implicit self-esteem. Personality and Individual Differences, 50, 747-750. doi:10.1016/j.paid.2010.11.025

Sulsky, L. M. \& Kline, T. J. (2007). Understanding frame of reference training success: A social learning theory perspective. International Journal of Training and Development, 11, 121131. 
Vallade, J. I., Booth-Butterfield, M., \& Vela, L. E. (2013). Taking back power: Using superiority theory to predict humor use following a relational transgression. Western Journal of Communication, 77, 231-248. doi:10.1080/10570314.2012.669018

Vela, L. E., Booth-Butterfield, M., Wanzer, M., \& Vallade, J. I., (2013). A transactional approach to humor orientation and coping with dating relationship stress. Communication Research Reports, 30, 68-75. doi:10.1080/08824096.2012.746224

Wanzer, M., \& Booth-Butterfield, M. (2012). Introduction to the measurement of humorous communication. In R. L. Dicioccio (Ed.), Humor communication: Theory, impact and outcomes (pp. 3-20). Dubuque, IA: Kendall/Hunt.

Wanzer, M., Booth-Butterfield, M., \& Booth-Butterfield, S. (1995). The funny people: A source-orientation to the communication of humor. Communication Quarterly, 43, 142-154. doi:10.1080/01463379509369965

Wanzer, M., Booth-Butterfield, M., \& Booth-Butterfield, S. (1996). Are funny people more popular: The relationship of humor orientation, loneliness, and social attraction. Communication Quarterly, 44, 42-52. doi:10.1080/01463379609369999

Wanzer, M. \& Frymier, A. B. (1999). The relationship between student perceptions of instructor humor and students' reports of learning. Communication Education, 48, 48-61.

Wexley, K. N., \& Latham, G. P. (1991). Developing and training humor resources in organizations. New York, NY: Harper Collins.

Yip, J. A., \& Martin, R. A. (2006). Sense of humor, emotional intelligence, and social competence. Journal of Research in Personality, 40, 1202-1208. 
Yue, X. D., \& Goldman, G. L. (2010). Humor styles, dispositional optimism, and mental health among undergraduates in Hong Kong and China. Journal of Psychology in Chinese Societies, 11, 173-188.

Zillman, D. (1983). Disparagement humor. In P. E. McGhee \& J. H. Goldstein (Eds.), Handbook of humor research (Vol. 1, pp. 85-108). New York, NY: Springer. 


\section{Appendix A \\ Humor Orientation Scale}

Instructions: Below are several descriptions of how you may communicate in general. Please use the scale below to rate the degree to which each statement applies to your communication.

\begin{tabular}{|ccccc|}
\hline Strongly Disagree & Disagree & Neutral & Agree & Strongly Agree \\
$\mathbf{1}$ & $\mathbf{2}$ & $\mathbf{3}$ & $\mathbf{4}$ & $\mathbf{5}$ \\
\hline
\end{tabular}

1. I regularly tell jokes and funny stories when in a group.

2. People usually laugh when I tell jokes or funny stories.

3. I have no memory for jokes or funny stories.

4. I can be funny without having to rehearse a joke.

5. Being funny is a natural communication style with me.

6. I cannot tell a joke well.

7. People seldom ask me to tell stories.

8. My friends would say I am a funny person.

9. People don't seem to pay close attention when I tell a joke.

10. Even funny jokes seem flat when I tell them.

11. I can easily remember jokes and stories.

12. People often ask me to tell jokes or stories.

13. My friends would not say that I am a funny person.

14. I don't tell jokes or stories even when asked to.

15. I tell stories and jokes very well.

16. Of all the people I know, I am one of the funniest.

17. I use humor to communicate in a variety of situations. 


\section{Appendix B \\ Humor Styles Questionnaire}

Instructions: Below are several descriptions of how you may communicate in general. Please use the scale below to rate the degree to which each statement applies to your communication.

\begin{tabular}{|ccccc|}
\hline Strongly Disagree & Disagree & Neutral & Agree & Strongly Agree \\
$\mathbf{1}$ & $\mathbf{2}$ & $\mathbf{3}$ & $\mathbf{4}$ & $\mathbf{5}$ \\
\hline
\end{tabular}

1. I usually don't laugh or joke around much with other people.

2. If I am feeling depressed, I can usually cheer myself up with humor.

3. If someone makes a mistake, I will often tease them about it.

4. I let people laugh at me or make fun at my expense more than I should.

5. I don't have to work very hard at making other people laugh - I seem to be a naturally humorous person.

6. Even when I'm by myself, I am often amused by the absurdities of life.

7. People are never offended or hurt by my sense of humor.

8. I will often get carried away in putting myself down if it makes my family or friends laugh.

9. I rarely make other people laugh by telling funny stories about myself.

10. If I am feeling upset or unhappy I usually try to think of something funny about the situation to make myself feel better.

11. When telling jokes or saying funny things, I am usually not very concerned about how other people are taking it.

12. I often try to make people like or accept me more by saying something funny about my own weaknesses, blunders, or faults.

13. I laugh and joke a lot with my closest friends.

14. My humorous outlook on life keeps me from getting overly upset or depressed about things.

15. I do not like it when people use humor as a way of criticizing or putting someone down.

16. I don’t often say funny things to put myself down. 
17. I usually don't like to tell jokes or amuse people.

18. If I'm by myself and I'm feeling unhappy, I make an effort to think of something funny to cheer myself up.

19. Sometimes I think of something that is so funny that I can't stop myself from saying it, even if it is not appropriate for the situation.

20. I often go overboard in putting myself down when I am making jokes or trying to be funny.

21. I enjoy making people laugh.

22. If I am feeling sad or upset, I usually lose my sense of humor.

23. I never participate in laughing at others even if all my friends are doing it.

24. When I am with friends or family, I often seem to be the one that other people make fun of or joke about.

25. I don't often joke around with my friends.

26. It is my experience that thinking about some amusing aspect of a situation is often a very effective way of coping with problems.

27. If I don't like someone, I often use humor or teasing to put them down.

28. If I am having problems or feeling unhappy, I often cover it up by joking around, so that even my closest friends don't know how I really feel.

29. I usually can't think of witty things to say when I'm with other people.

30. I don't need to be with other people to feel amused - I can usually find things to laugh about even when I'm by myself.

31. Even if something is really funny to me, I will not laugh or joke about it if someone will be offended.

32. Letting others laugh at me is my way of keeping my friends and family in good spirits 


\section{Appendix C \\ Cognitive Learning Assessment}

Instructions: Please circle the multiple-choice response that most accurately answers the question or completes the sentence.

1. People who enact humor frequently and successfully, and perceive themselves as effective in communicating humor have a
a) High humor orientation
b) Low humor orientation
c) High humor style
d) Low humor style

2. Which of the following are less concerned with how people react to different types of situations by using humor and laughter, and more on how individuals use positive and/or negative humor in their daily lives?
a) Humor orientation
b) Humor style
c) Humor personality
d) Humorous individuals

3. Which type of humor is used to benefit the self and interpersonal relationships?
a) Adaptive humor
b) Relational humor
c) Laughter
d) Maladaptive humor

4. Which humor style is used as a coping mechanism to adapt to stressful situations?
a) Affiliative humor
b) Aggressive humor
c) Self-enhancing humor
d) Self-disparaging humor

5. Moments before having to discuss a difficult topic with a close friend, Josh told a joke to ease his own stress. This is an example of which humor style?
a) Affiliative humor
b) Aggressive humor
c) Self-enhancing humor
d) Self-disparaging humor

6. Which humor style is employed to amuse others, create interpersonal relationships, and reduce tension, through the use of light-hearted jokes and witty communication?
a) Affiliative humor
b) Aggressive humor
c) Self-enhancing humor
d) Self-disparaging humor 
7. During introductions on the first day of class, Melissa told a joke to try and get her classmates to like her. This is an example of which humor style?
a) Affiliative humor
b) Aggressive humor
c) Self-enhancing humor
d) Self-disparaging humor

8. Which type of humor is used to communicate aggressive messages, manipulate others, and is viewed as destructive for the self?
a) Adaptive humor
b) Relational humor
c) Laughter
d) Maladaptive humor

9. Which humor style is used to hurt or put others down through the use of sarcasm, teasing, and ridicule?
a) Affiliative humor
b) Aggressive humor
c) Self-enhancing humor
d) Self-disparaging humor

10. Frank was having trouble putting together his new dorm furniture, so his roommate Tom made fun of Frank by teasing him and making harsh comments disguised as jokes. This is an example of which humor style?
a) Affiliative humor
b) Aggressive humor
c) Self-enhancing humor
d) Self-disparaging humor

11. Which humor style is used to gain others' approval though intentionally making oneself the "butt" of the joke?
a) Affiliative humor
b) Aggressive humor
c) Self-enhancing humor
d) Self-disparaging humor

12. John was embarrassed about finishing the race in last place, so as he crossed the finish line he cracked a joke about "saving the best for last!" This is example of which humor style?
a) Affiliative humor
b) Aggressive humor
c) Self-enhancing humor
d) Self-disparaging humor 


\section{Appendix D \\ Self-efficacy Scale}

Instructions: Positive humor involves intentional verbal and nonverbal messages that elicit pleasure, delight, and/or surprise in the receiver (e.g., lighthearted joke). Negative humor involves intentional verbal and nonverbal messages used to communicate aggressive messages and/or manipulate others (e.g., putdowns, sarcasm). Using the scale below, please rate how confident you are that you can communicate humor in each of the following situations.

\section{Cannot do at all} o 1

1. How confident are you in your ability to use positive humor in daily conversation.

2. How confident are you in your ability to use positive humor when discussing sensitive information.

3. How confident are you in your ability to use positive humor when involved in a conflict.

4. How confident are you in your ability to use positive humor to diffuse tension.

5. How confident are you in your ability to use positive humor in a stressful situation.

6. How confident are you in your ability to use positive humor when you are angry or annoyed.

7. How confident are you in your ability to use positive humor when you are happy.

8. How confident are you in your ability to use positive humor in general.

9. How confident are you in your ability to avoid using negative humor in daily conversation.

10. How confident are you in your ability to avoid using negative humor when discussing sensitive information.

11. How confident are you in your ability to avoid using negative humor when involved in a conflict.

12. How confident are you in your ability to avoid using negative humor to diffuse tension.

13. How confident are you in your ability to avoid using negative humor in a stressful situation.

14. How confident are you in your ability to avoid using negative humor when you are angry or annoyed. 
15. How confident are you in your ability to avoid using negative humor when you are happy.

16. How confident are you in your ability to avoid using negative humor in general. 


\section{Appendix E \\ Motivation Scale}

Instructions: Below are several descriptions of how you may communicate in general. Please use the scale below to rate the degree to which each statement applies to your communication.

\begin{tabular}{|ccccc|}
\hline Strongly Disagree & Disagree & Neutral & Agree & Strongly Agree \\
$\mathbf{1}$ & $\mathbf{2}$ & $\mathbf{3}$ & $\mathbf{4}$ & $\mathbf{5}$ \\
\hline
\end{tabular}

1. I am self-motivated to use positive humor.

2. I want to know more about how to use positive humor.

3. I want to practice using positive humor.

4. I want to use positive humor in most situations.

5. I am self-motivated to avoid using negative humor.

6. I want to know more about how to avoid using negative humor.

7. I want to practice avoiding using negative humor.

8. I want to avoid using negative humor in most situations. 


\section{Appendix F \\ Humor Use Scale}

Instructions: Positive humor involves intentional verbal and nonverbal messages that elicit pleasure, delight, and/or surprise in the receiver (e.g., lighthearted joke). Negative humor involves intentional verbal and nonverbal messages used to communicate aggressive messages and/or manipulate others (e.g., putdowns, sarcasm). Using the scale below, indicate how often you have engaged in each of the following behaviors in the past month.

\begin{tabular}{|ccccc|}
\hline Never & Rarely & Sometimes & Often & Very Often \\
$\mathbf{1}$ & $\mathbf{2}$ & $\mathbf{3}$ & $\mathbf{4}$ & $\mathbf{5}$ \\
\hline
\end{tabular}

\section{In the past month:}

1. I successfully used positive humor.

2. I found it easy to use positive humor.

3. I used positive humor effectively in a variety of situations.

4. I successfully avoided using negative humor.

5. I found it easy to avoid using negative humor.

6. I avoided using negative humor in a variety of situations.

\section{Open-ended Responses}

1. In as much detail as possible, explain a time in the last month when you successfully used positive humor in an interaction (e.g., What was the humor about? Who did you use it with?)

2. In as much detail as possible, explain a time in the last month when you successfully avoided using humor in an interaction (e.g., What was the situation? How did you avoid using negative humor? What did you say instead?) 


\section{Appendix G \\ Humor Communication Skills Training Outline}

\section{A. Introduction - Complete Questionnaire}

\section{B. Communicating Effectively}

1. Communication is often a problem in interpersonal interactions. During the next few class sessions, we'll look at what the problem is and how communication can work to solve or at least make it better. Then we will work to change the communication.

2. The ultimate goal:

C. Communication Competence is composed of 3 elements: knowledge, skill, and motivation

1. Knowledge - cognitive components

a. Content vs. Procedural Knowledge

\section{Skill Components}

\section{Motivation}




\section{Humor and Communication Competence}

1. Humor as an interpersonal skill may help
a.
b.
c.

\section{E. Personality and Communication}

\section{Predispositions/Personality traits}

\section{Humor Orientation}

a. Definition:

b. High vs. Low 


\section{F. Humor Styles}

1. Definition:

\section{G. Positive/Adaptive Humor}

\section{Affiliative humor}

a. Definition:

b. Examples of affiliative humor

\section{Self-enhancing humor}

a. Definition:

b. Examples of self-enhancing humor 


\section{Positive Humor and Relationships}

\section{H. Negative/Maladaptive Humor}

\section{Self-defeating humor}

c. Definition:

d. Examples of self-defeating humor 


\section{Aggressive humor}

c. Definition:

d. Examples of aggressive humor

e. Aggressive humor triggers

3. Negative Humor and Relationships 
I. Humor Styles in Action

J. Learning and Behavioral Change

1. Social Cognitive Theory (SCT)

2. Self-efficacy

a. Definition:

b. Examples of self-efficacy 
Appendix H

Humor Communication Skills Training PowerPoint Presentation 


\section{Appendix I \\ Outline for Sexual Communication Skills Training}

*Overview of Skills Training*

A. Intimacy versus Sexuality

B. Orientations toward Sexuality

C. Who is having sex? And should they be?

a. What are the trends?

b. Special risks with sexual activity at a young age.

D. Condom Use

a. What affects how we communicate about potentially risky behaviors?

b. Ethnic differences. 
E. Male and female sexual attitude behavior differences.

F. Pregnancy as an Outcome

G. Sex talk and intimacy - how do you know when someone is ready to become physically intimate with you?

H. Negotiating sexual intimacy - Communication and sexual satisfaction

a. Why are we uncomfortable talking about sexual interactions?

b. Discussion patterns - What DO we talk about?

c. Negative games people play with sexual communication.

d. How to communicate more effectively with your sexual partner? 
Appendix J

Sexual Communication Skills Training PowerPoint Presentation 


\section{Appendix K}

\section{Handout for Humor Communication Skills Training}

Sexual Relationship Issue 1

Please read the scenario carefully and answer the questions that follow.

Michelle and Michael are generally happy in their relationship, but there is something that has been bothering Michael. He feels like their sex life is becoming predictable, and he would like to spice things up. For the past several weeks they have been doing the exact same thing every time they have sex. He went out and bought a book that has lots of different sexual positions, and he would like to suggest to Michelle that they try some of them. He has tried to hint to her that he wants to try new things by nudging her and trying to move into different positions during sex, but she does not seem to be picking up on it. He has not said anything directly, because he is afraid that Michelle will react negatively to his suggestion. He does not want her to think that he is demanding and critical, or that he is being needy. So instead of saying anything, he leaves the book in the back of the closet, and continues to feel dissatisfied with this part of their relationship.

1. How much do you like Michael?

$\begin{array}{lllllllll}\text { Not at all } & 1 & 2 & 3 & 4 & 5 & 6 & 7 & \text { Very much so }\end{array}$

2. Given the situation, how reasonable is Michael's desire to change the way his relationship with Michelle is going?

$\begin{array}{lllllllll}\text { Not at all } & 1 & 2 & 3 & 4 & 5 & 6 & 7 & \text { Very much so }\end{array}$

3. Given the situation, how reasonable is Michael's suggestion for changing the relationship?

$\begin{array}{lllllllll}\text { Not at all } & 1 & 2 & 3 & 4 & 5 & 6 & 7 & \text { Very much so }\end{array}$

4. How common do you think Michael's situation is?

$\begin{array}{lllllllll}\text { Not at all } & 1 & 2 & 3 & 4 & 5 & 6 & 7 & \text { Very much so }\end{array}$

5. Do you know anyone that can identify with Michael's point of view in this situation?

$\begin{array}{lllllllll}\text { Not at all } & 1 & 2 & 3 & 4 & 5 & 6 & 7 & \text { Very much so }\end{array}$

6. What additional comments, if any, do you have about Michael? 


\section{Sexual Relationship Issue 2}

Please read the scenario carefully and answer the questions that follow.

Michael and Michelle are generally happy in their relationship, but there is something that has been bothering Michelle. She feels like their sex life is becoming predictable, and she would like to spice things up. For the past several weeks they have been doing the exact same thing every time they have sex. She went out and bought a book that has lots of different sexual positions, and she would like to suggest to Michael that they try some of them. She has tried to hint to him that he wants to try new things by nudging him and trying to move into different positions during sex, but he does not seem to be picking up on it. She has not said anything directly, because she is afraid that Michael will react negatively to her suggestion. She does not want him to think that she is demanding and critical, or that she is being needy. So instead of saying anything, she leaves the book in the back of the closet, and continues to feel dissatisfied with this part of their relationship.

1. How much do you like Michelle?

$\begin{array}{lllllllll}\text { Not at all } & 1 & 2 & 3 & 4 & 5 & 6 & 7 & \text { Very much so }\end{array}$

2. Given the situation, how reasonable is Michelle's desire to change the way her relationship with Michael is going?

$\begin{array}{lllllllll}\text { Not at all } & 1 & 2 & 3 & 4 & 5 & 6 & 7 & \text { Very much so }\end{array}$

3. Given the situation, how reasonable is Michelle's suggestion for changing the relationship?
Not at all
1
23
4
5
$6 \quad 7 \quad$ Very much so

4. How common do you think Michelle's situation is?

$\begin{array}{lllllllll}\text { Not at all } & 1 & 2 & 3 & 4 & 5 & 6 & 7 & \text { Very much so }\end{array}$

5. What additional comments, if any, do you have about Michelle? 